تصور مقترح لتقييم الأداء المهني لمعلمي التربية الرياضية

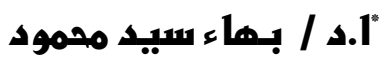

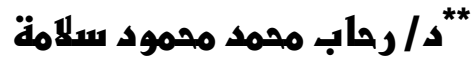
"الباهث/ فرهان كامل فرهان

مقدمة: - مقي

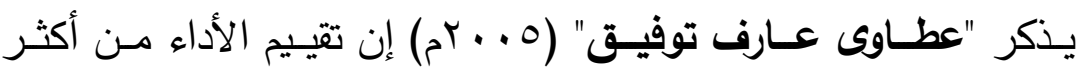

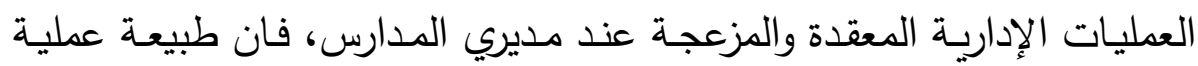

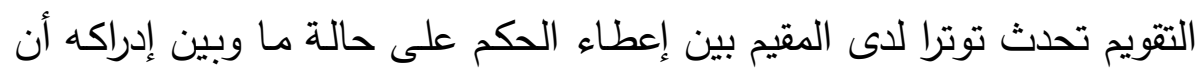

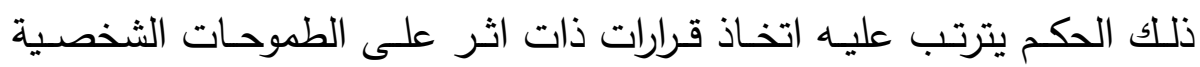

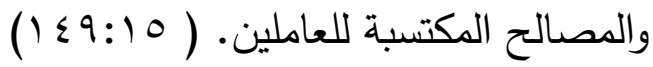

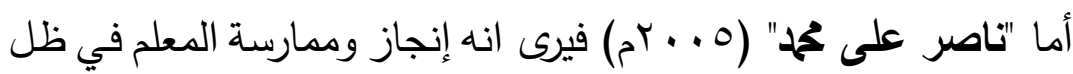

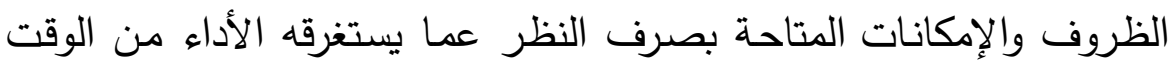

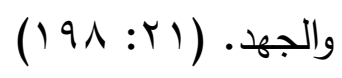

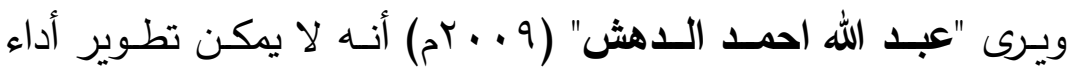

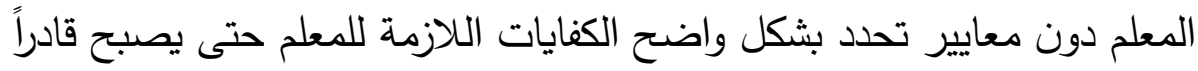

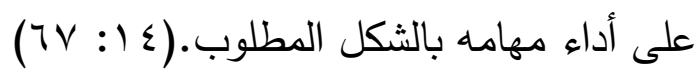

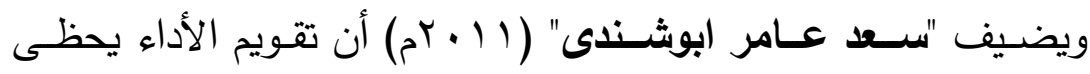

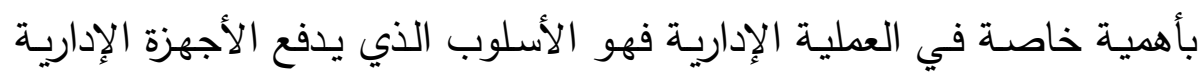

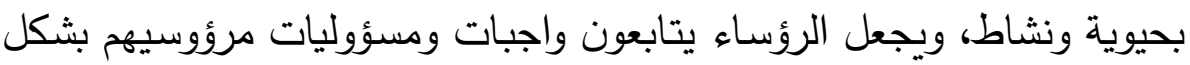

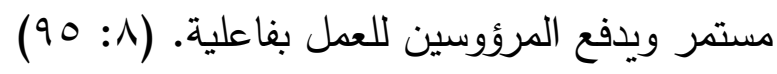

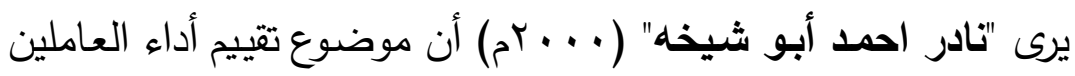

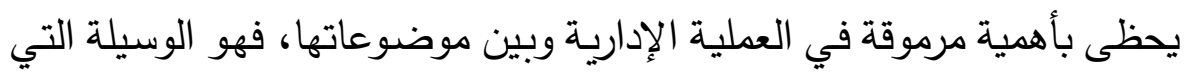

"عبد كلية التربية الرياضية بالوادي الجديد، أستاذ المناهج وتنريس التربية الرياضية بجامعة أسيوط

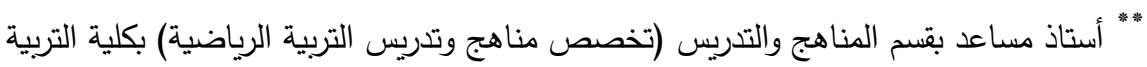
الرياضية- جامعة المنوفية.

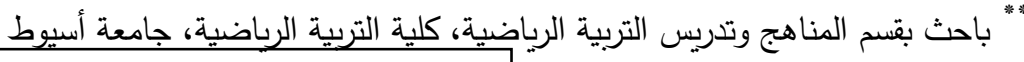

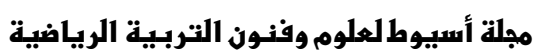


تدفع الأجهزة الإدارية للعمل بحيوية ونشاط، حيث تجعل الرؤساء يتابعون واجبات

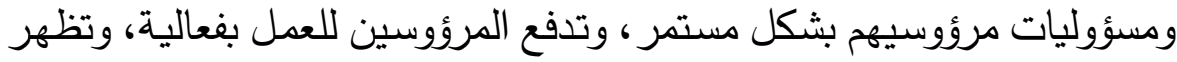

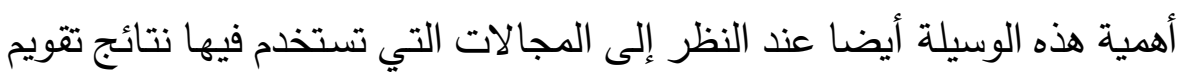
الأداء، وأهمها : تحسين أداء الموظف وتطويره، واعتماد هذا التقويم وسيلة لتحديد المكافآت والعلاوات الدورية، وأداة للكشف عن الاحتياجات التدريبية، ووسيلة

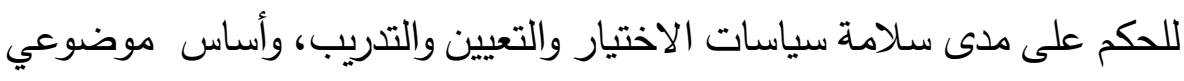

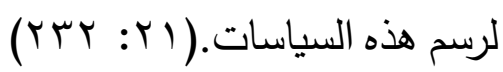

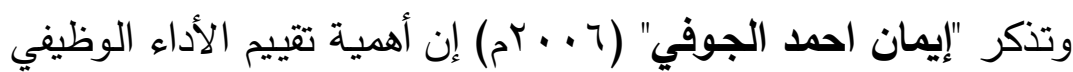

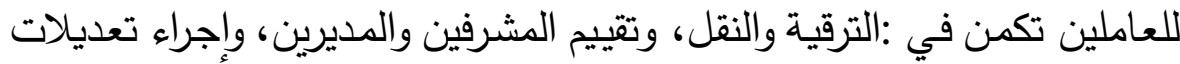

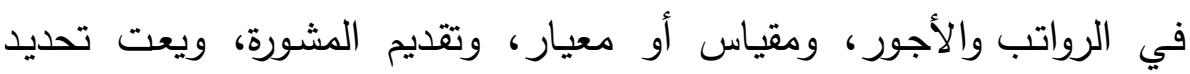
الاحتياجات التدريبية. (ع: V VT)

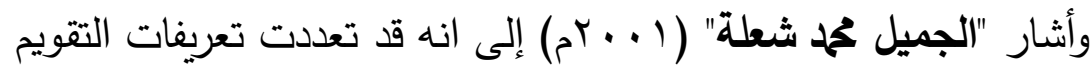
التربوي، فنها من أعتبر التقويم مرادفاً للقياس التربوي ومنها من اعتبره إصدئ إندار

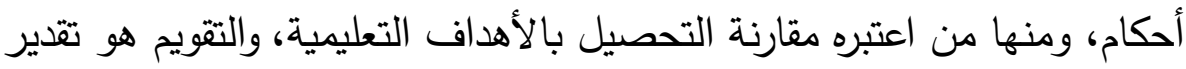

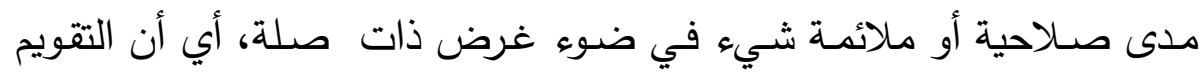

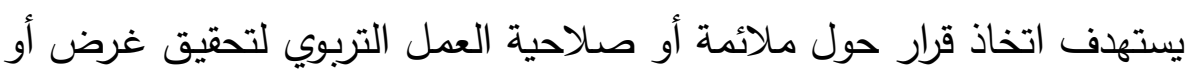

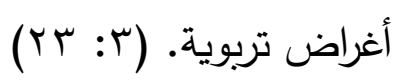

هناك شروط كثيرة يجب أن تتوافر عند تقويم أداء المعلم حتى ينجح هذا

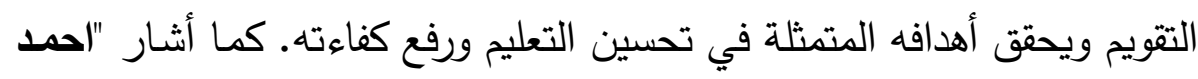

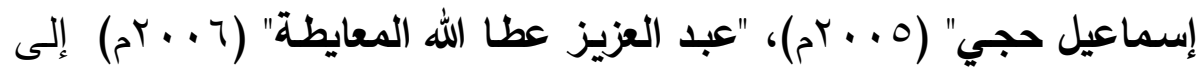

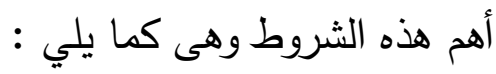
- الثمول: إذ يجب أن يشتمل تقويم المعلم على كافة الجوانب والأنشطة التي يقوم بها، ولا يجب التركيز على جوانب معينة دون الجوانب الأخرى. 
- الإيضـاح: كما يجب أن يوضـح التقويم مواطن الضعف وكيفية علاجها

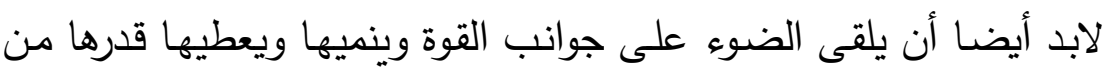

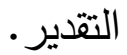

- - المشـاركة: ويتحقق ذلك عندما يثـارك مدير المدرسـة المشرف التربوي

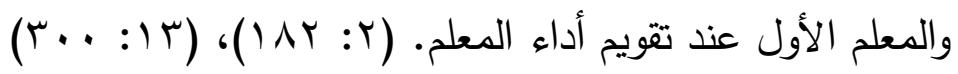

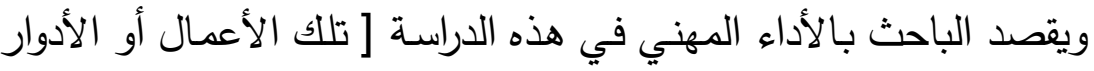

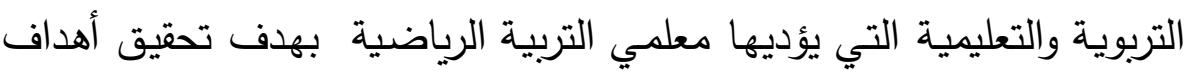

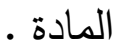

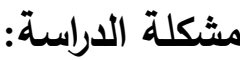

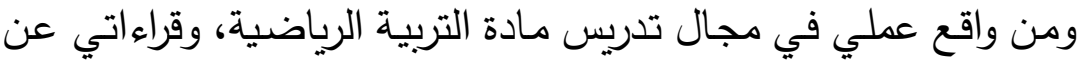
التقويم التربوي أرى أن الأدوات والأساليب والمعايير المستخدمة في تقيم أداء

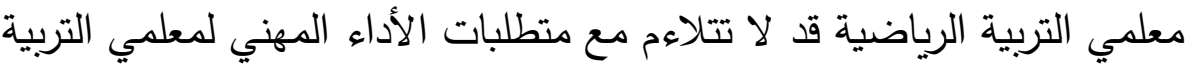

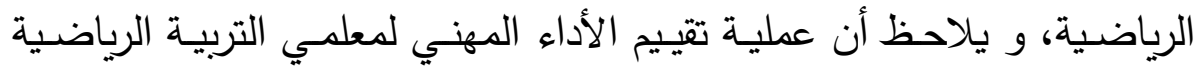

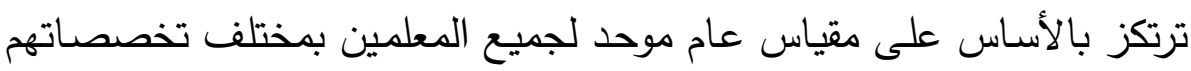
التدريسية، حيث يقاس أداء جميع المعلمين بنفس المعايير الموجودة باستمارة

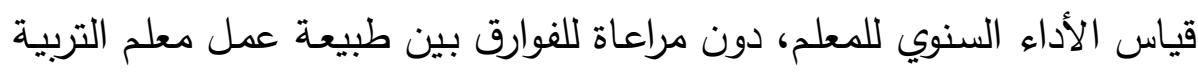

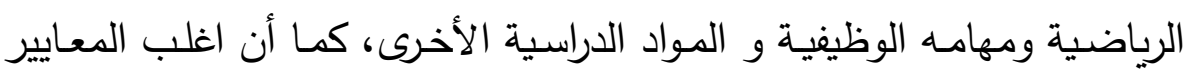

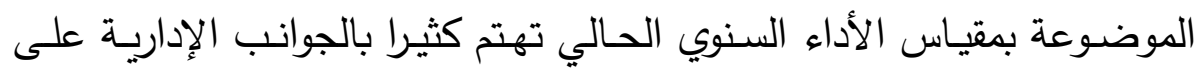

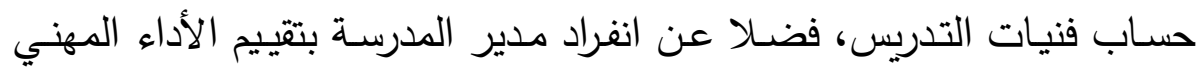
لمعلمي التربية الرياضية وباقي المعلمين. وأرى أن عملية تقيم أداء معلمي التربية الرياضية تتطلب وجين وجود معايير

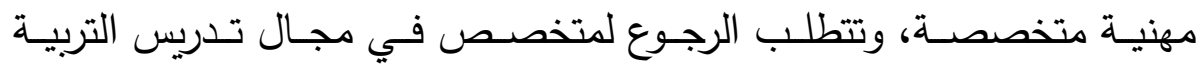

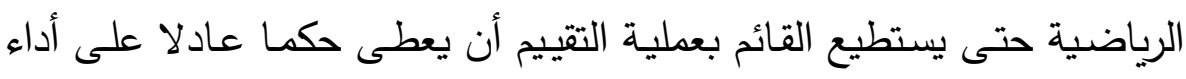

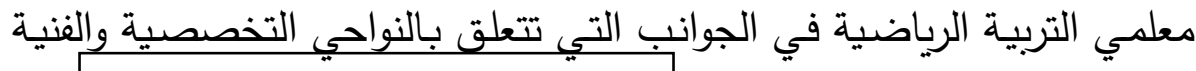
مجالة أسيوط لعلوم وفنون التربية الرياضية بلية لإية 
لتدريس مادة التربية الرياضية. وهو ما دفعني للقيام بهذه الدراسة تحت عنوان:

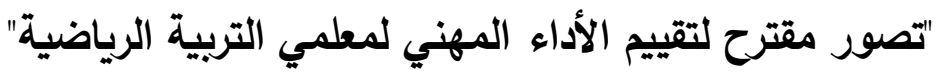
أهمية الدراسة والحاجة إليه:

- - تتناول الدراسة جزء بالغ الأهمية بالنسبة لمعلم التربية الرياضية وهو تقييم الأداء المهني لمعلمي التربية الرياضية، وما يترتب عليه من نتائج تؤثر بأثريه بشكل كبير على مستقبل المعلم المهني والمادي. - - تلقى الدراسة الضوء على المعايير التي يمكن استخدامها عند تقيم الأداء المهني لمعلمي التربية الرياضية. - - قد تفيد الدراسـة في إلقاء الضوء على المعايير التي يجب الاستناد إليها عند تقيـيم الأداء المهني لمعلمي التربيـة الرياضـية للوصـول إلى نتائج صادقة عن المستوى المهني لمعلم التربية الرياضية.

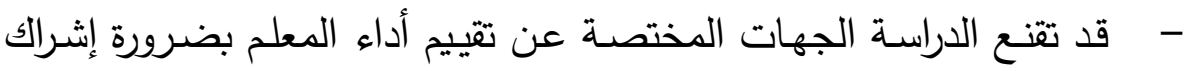
متخصصين في مجال التربية الرياضية أو الرجوع إليهم عند الشروع في تقييم الأداء المهني لمعلمي التربية الرياضية. هدف الدراسة: ا - تحديـد قائمسة بالمعـايير التي يمكن اسـتخدامها عـن تقيـيم الأداء المهني لمعلمي التربية. ץ- الوصول إلى تصور مقترح لتقييم الأداء المهني لمعلي التربية الرياضية. تساؤلات الدراسةة:

1- ما نقاط القوة والضعف في مقياس الأداء السنوي بشكله الحالي؟ r- مـا الأسـاليب والأدوات التي يسـخدمها مـدير المدرسـة عند تقيـيم الأداء المهني لمعلمي التربية الرياضية؟

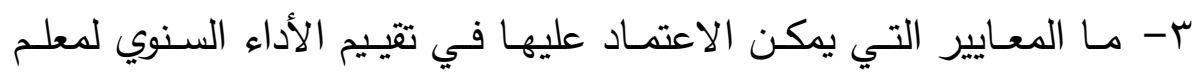

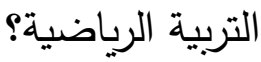




\section{مصطاحات الدراسة:}

- التقويم التربوي: Educational Evaluation

التقويم هو تقدير مدى صلاحية أو ملائمة شيء في ضوء أغراض ذات

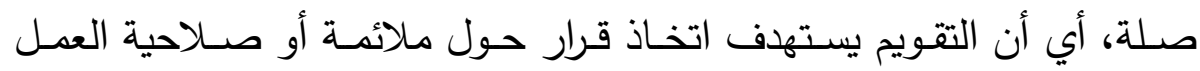

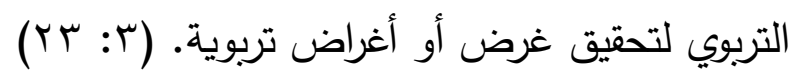

- تقييم الأداء : هي العمليـة التي تهدف إلى تقدير وقياس الأداء في ضـوء المعايير والمتطلبات الخاصة بالوظيفة التي يشغلها الفرد لغرض تحقيق بعض الأهداف ولى

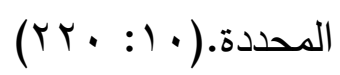

- الأداء الوظيفي: Functionality -

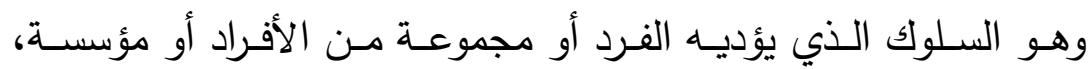
لتحقيـق هـدف معـين، ويتضـح هـذا السـلوك في أعمـال وتصـرفات الأفـراد. (91: :IV)

Standards: المعايير أن المعايير هي" تلك العبارات التي يمكن من خلالها تحديد المستوى الملأئم، والمرغوب من إتقان المحتوى والمهارات والأداءات وفرص التعلم ومعايير

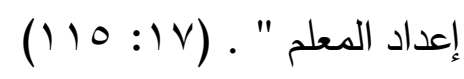

- القياس: Measurement هو تعين فئة من الأرقام أو الرموز تناظر سمات أو خصسائص الأفراد طبقا لقواعد محددة تحديدا جيدا. (1): 0 (1)

الاراسات المرتبطة: 


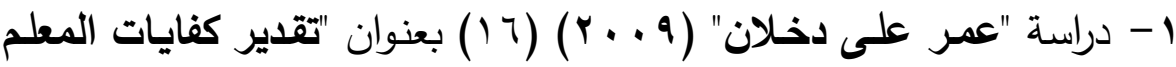
المسـاند مـن وجهـه نظر مديري المـارس والمشـرفين التربوينين"، واتبع الباحث المـنهج الوصـفي وهدفت الدراسـة إلى التعـرف على أراء مـديري المدارس والمشرفين التربوين حول ما يمتلكه المعلم المساند من كفايات

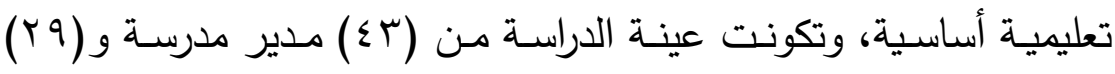

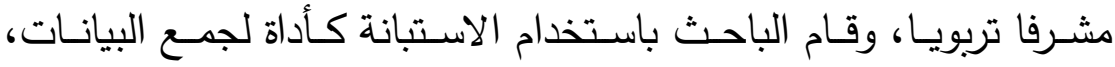

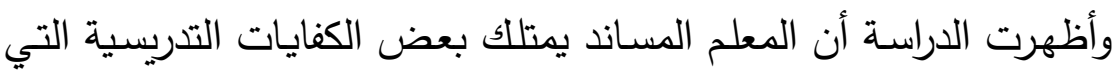
تتعلق بالمجالات الآتية: التخطيط اليومي وإثارة الدافعية والإدارة الصفية والمرونـة وتقبل التلاميذ، وانه بحاجة إلى تطوير نفسـه في بعض كفاياته

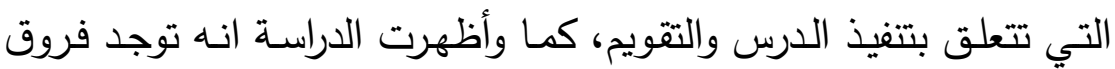
ذات دلالة إحصائية تعزى لمتغير نوع الوظيفة والمؤهل الدراسي وسنوات الخبرة.

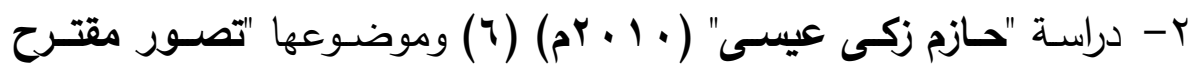
لتطوير الأداء التدريسي لمعلمي العلوم وفق معايير الجودة في المرحلة

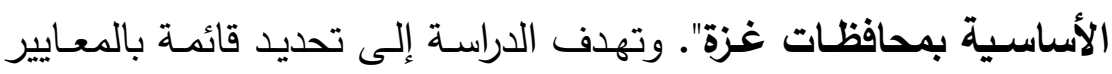

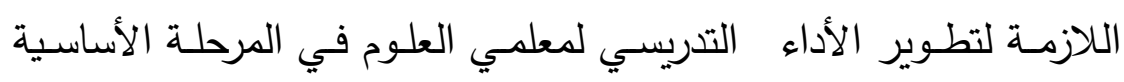
وتحديد المعايير اللازمة لمعلمي العلوم في المرحلـة الأساسية من وجهة نظر معلمي العلوم، ومعرفة مدى توافر هذه المعايير للى مجموعـة من

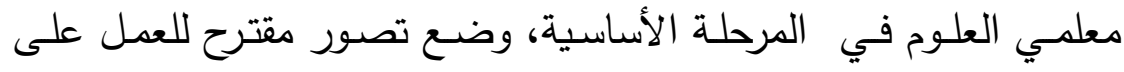
تطوير أداء المعلم في ضـوء هذه المعايير .تمثلت عينـة الدراسـة من عدد

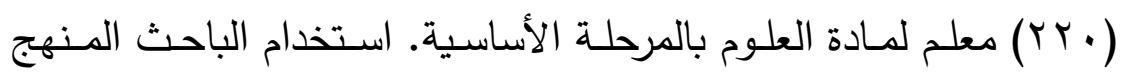

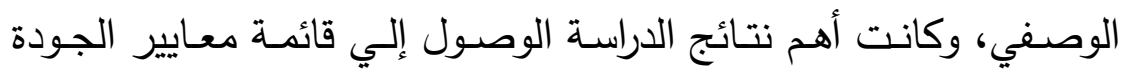

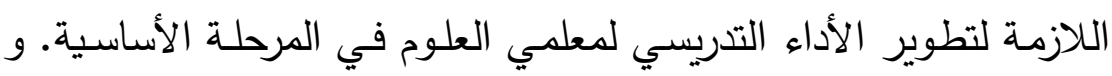

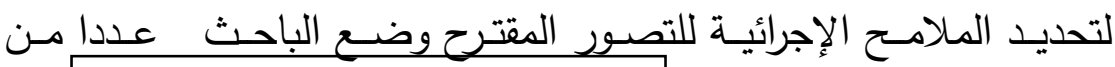
مجلة أسيوط لعلوم وفنون التربية الرياضية 
الخطوات والمهام التي يمكن إتباعها من قبل مديريات التربية والتعليم بوزارة التربية والتعليم الفلسطينية.

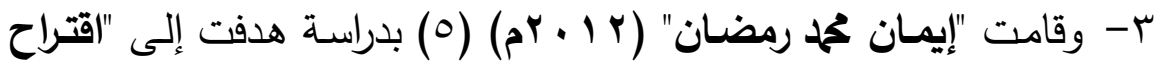

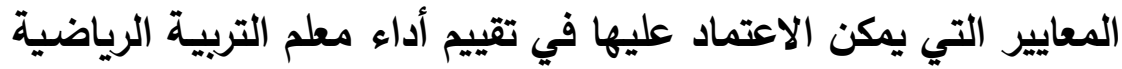

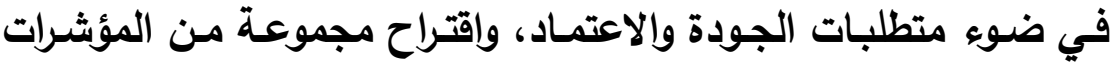

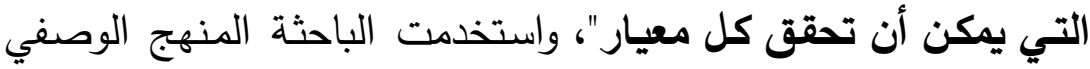

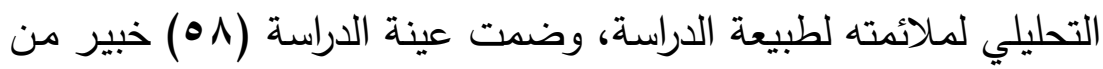

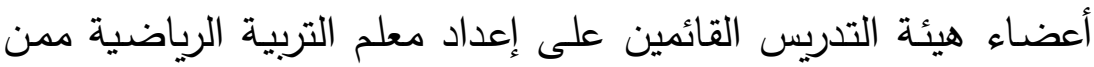

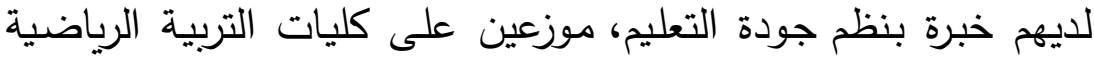
بجمهورية مصر العربية في نطاق ست محافظات، وكذلك (1ه) من موجهي التربية الرياضية في ستة إدارات تعليمية في نطاق محافظتين، وذلك للوقوف على إمكانية تطبيق هذه المؤشرات على معلمي التربية

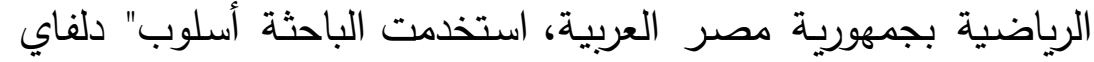

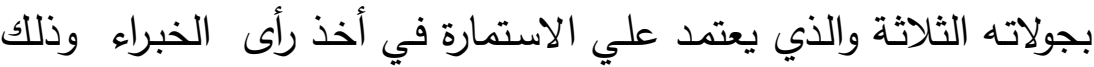
للوقوف علي قائمة المعايير التي يمكن الاعتماد عليها في تقييم أداء معلمي التربية الرياضية، وتوصلت الدراسة إلى ضرورة تطبيق المعايير المقترحة على معلمي التربية الرياضية بجمهورية مصر العربية نظرا للدور المهم الذي يقوم به في تتمية المجتمع بدنيا ونفسيا.

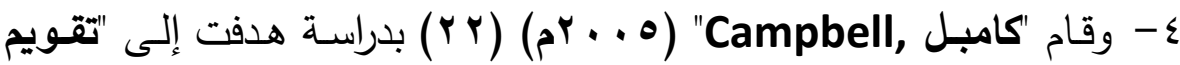

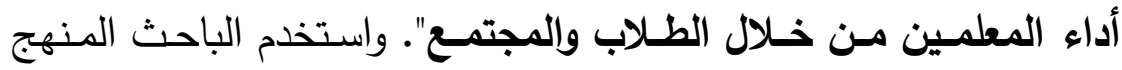

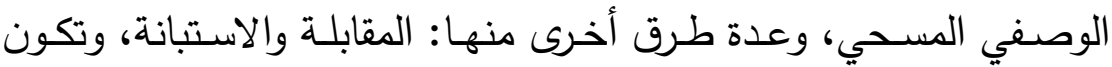

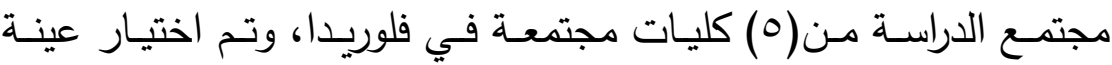
عشوائية طبقية، تكونت من (TON) من الطلبة وأعضاء هيئة التدريس

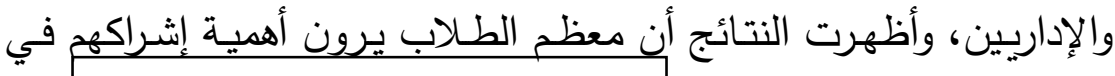
مجلة أسيوط لعلوم وفنون التربية الرياضية 
تقويم أداء المعلم، في حين يرى طرف أخر انه ليس من الواجب أن يقيم

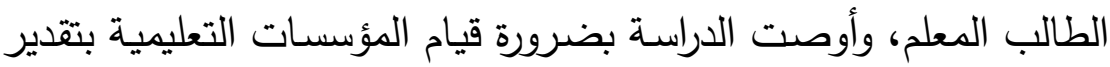
قيمـة ممارسـة الطـلاب لعملية تقويم المعلم وتحسين الإجراءات المتعلقـة بإدارة الطلاب لممارسة التقييم، واستطلاع رأيهم.

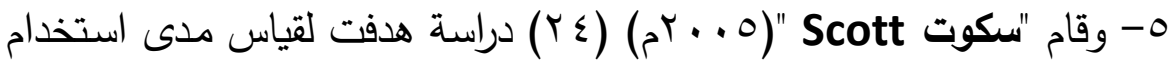
مديري الدارس الثانوية في مقاطعة اركنسس لطريقة تقويم الأداء للمعلمين

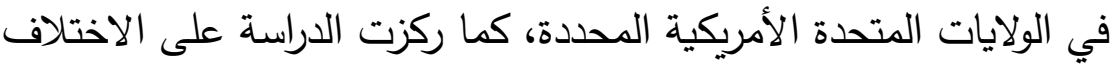
في استجابات وتصسورات مديري المدارس الثانويـة والمتوسطة، واستخدم

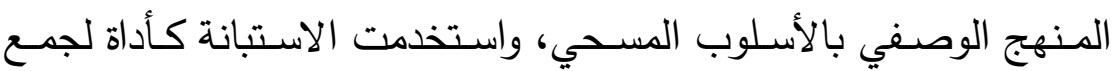

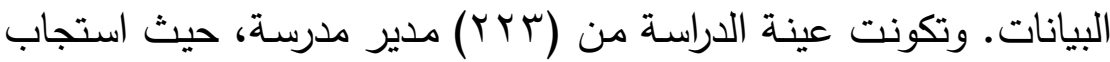

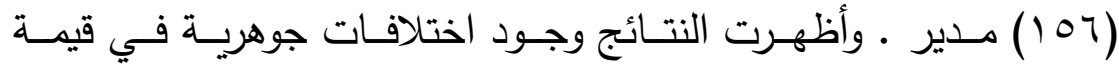

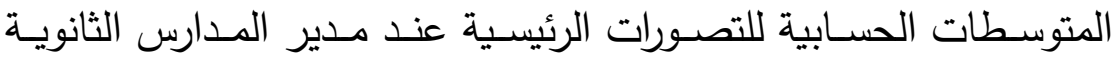

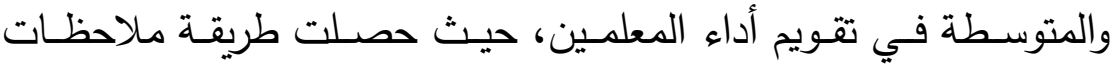

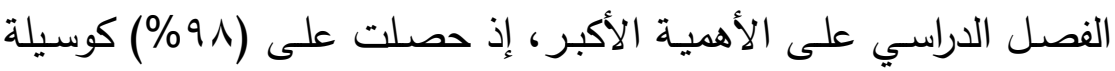

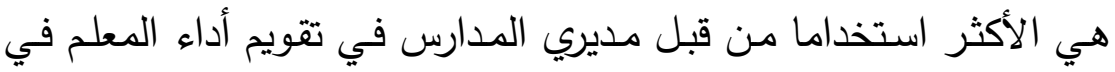

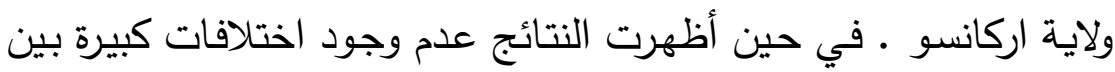

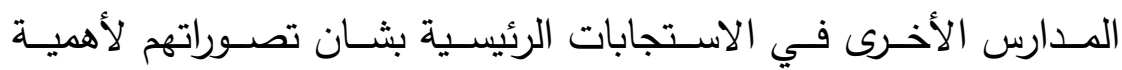
واستخدام أساليب تقييم أداء المعلم السبعة.

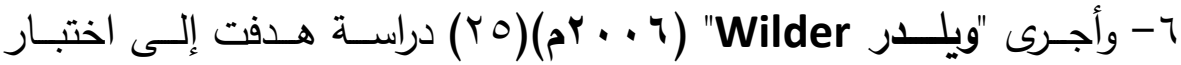
المصداقية والثـرعية والكفـاءات المتوقعـة والفعلية والخبرات لدى مديري

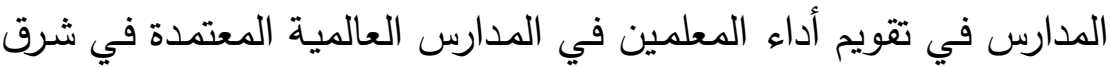

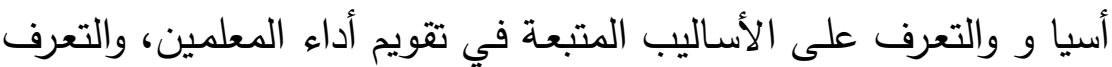

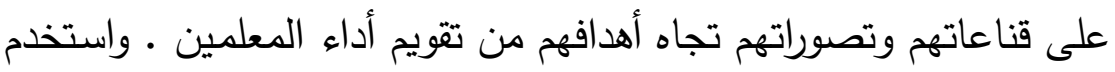

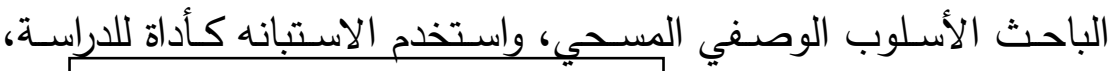

\section{مجلة أسيوط لعلوم وفنون التربية الرياضية}


وتكون مجتمع الدراسـة من جميع مديري المدارس العالميـة المعتمدة في شرق أسيا بمنطقة ايروكس • واشتملت عينة الدراسـة على (ع • ( ) مدير مليري

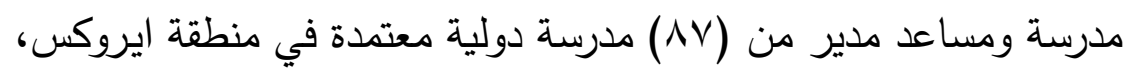

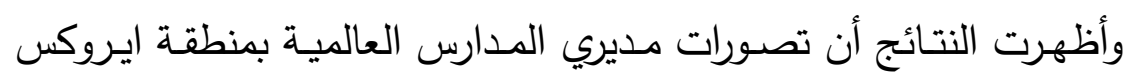
حول أهداف تقويم أداء المعلمين بأنه مسائلة لتجويد العمل وتحسين التعلم، ومتابعة المعلمين غير الأكفاء في الأداء، وتوصلت النتائج إلى أن مديري لهي المدارس العالمية في ايروكس يفتقرون إلى الخبرات والكفاءات والمؤهلات في تقيـيم أداء المعلمـين مثل الملاحظــة الصـفية، ويمارسـون الأسـاليب الحديثة في التقويم بدرجة اقل، وأوصت الدراسـة بضرورة تدريب المديرين على مهارات تقويم أداء المعلمين.

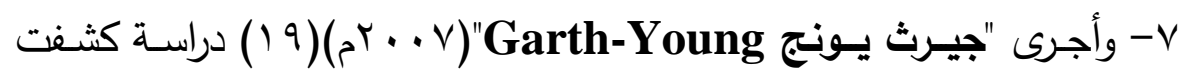
عن الأفاق المهنية لمديري المدارس العالية والمتوسطة في ولايـة الينوى بشـيكاغو فيمـا يتعلق بعمليـة تقـويم أداء المعلم، واستكثـاف المعوقـات،

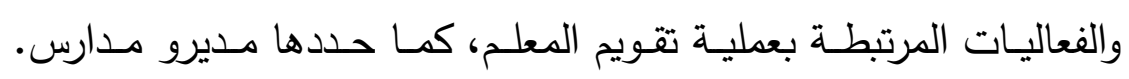
واستخدم الباحث المنهج الوصفي،كما استخدم الاستبانة كأداة للدراسة،حيث

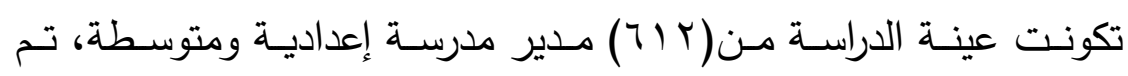
اختيارها بطريقة عشوائية وبسيطة من ولاية الينوى. وأظهرت نتائج الدراسة أن مديري المدارس يرون الهدف من تقويم المعلم هو : قياس كفاءة المعلم

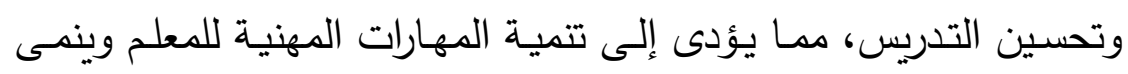
النمو المهني لهم، كما الأسس الخاصة بتقويم أداء المعلم قد تكون ممكنة إذا خصص لها الوقت الكافي لإجراء التقييمات، ولاحظ مديرو المدارس لهوسي أيضـا أهمية المناخ وبنـاء الثقة في العلاقات، ثم التوصل لأدلة تجريبية

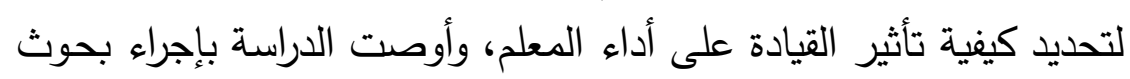
إضافية في هذا المجال قد تحسن عملية التقويم وترتقي بأداء المعلم. مجلة أسيوط لعلوم وفنون التربية الرياضية بإية 
التعليق على الدراسات المرتبطة : - الأهداف: يتضح من الدراسات السابقة أنها قد اهتمت بالتعرف على الطرق والأسـاليب التي يستخدمها مديري المـدارس في عملية تقيـيم وتقويم أداء

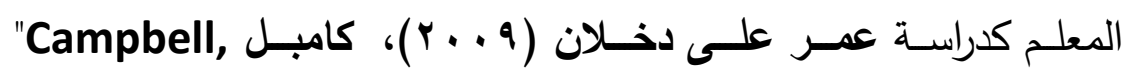

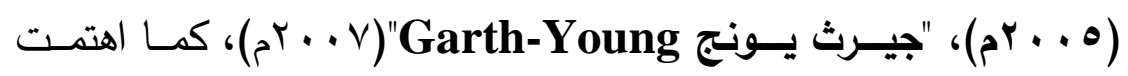

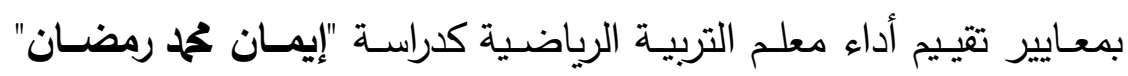

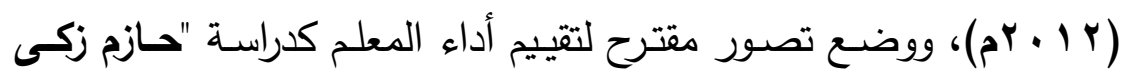

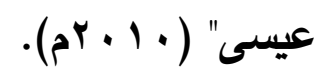

- - المـنهج: اتفقت اغلب الدراسـات السـابقة على اسـخدام المنهج الوصفي

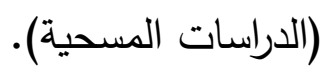

- العينة: اتفقت اغلب الدراسـات السابقة على استخدام عينات انحصرت في (المعلمين، والمـوجهين، ومديري المـدارس، والخبـراء في المنـاهج وطـرق

$$
\text { التدريس بالجامعات). }
$$

- - وسائل جمع البيانات: اتفقت معظم الدراسات السابقة على استخدام وسائل

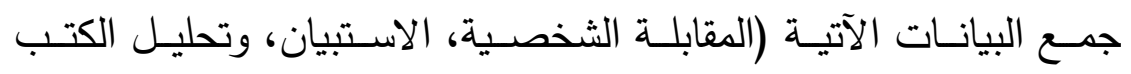
والمراجـع، والدراسـات السـابقة المرتبطـة بالدراسـة)، واختلفـت في وسـائل أخرى طبقاً لطبيعة وأهداف كل دراسة.

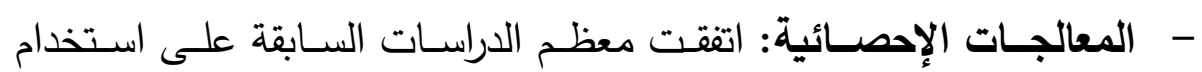

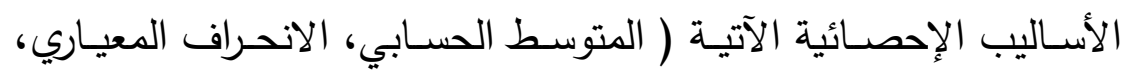

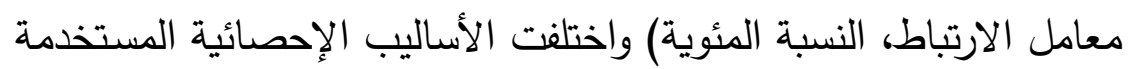
في تحليل البيانات لكل دراسة على حدة طبقاً لطبيعة وأهداف كل دراسة. الاستفادة التي تحققت من الاراسات المرتبطة: ا- سـاعدت الباحث على تحديد خطوات إجراء الدراسـة مما جعله أكثر قدرة على تحديد مسارها وتوجيهه لتحقيق الأهداف المرجوة. 
r- التعرف على العديد من المراجع العربية والأجنبية والدراسات المشابهة. ؟- ب تحديد المنهج الملائم والمناسب لطبيعة وأهداف الدراسة. ع - تحديد مجتمع وعينة الدراسة.

ه- تحديد أدوات جمع البيانات المناسبة للدراسة. 7- تحديد المعالجات الإحصائية المناسبة للدراسة.

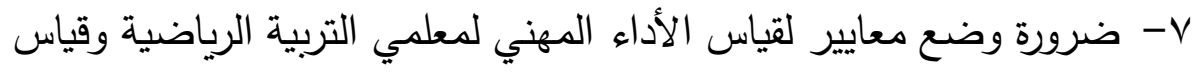

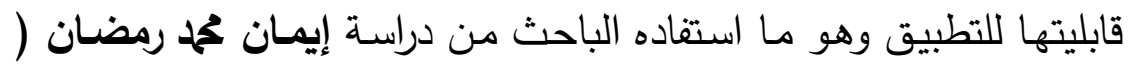

$$
.1 r
$$

- معرفـة وجهـات النظـر المتباينـة في الأسـاليب التي يسـتخدمها مـديري

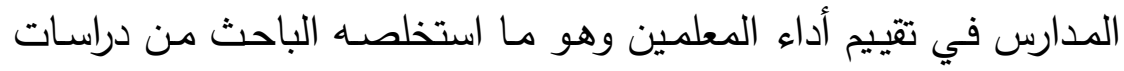

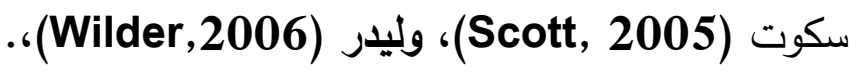

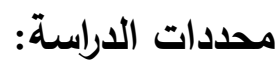
- الحدود الدكانيـة والجغرافيـة: المدارس الإعداديـة والثانويـة بمحافظـة الوادي الجديد. - الجن

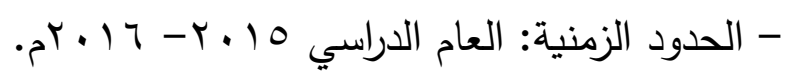
- الحدود البشرية: معلمي وموجهي التربية الرياضية، مديري المدارس بالوادي الترائ الجديد، خبراء في المناهج وتدريس التربية الرياضية.

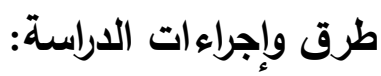
منهج الدراسة : مزاء يستخدم الباحث المنهج الوصفي " الدراسات المسحية " وذللك لملائمته

$$
\text { لمتمع الدراسة: }
$$

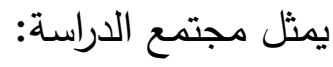


1- الخبراء المتخصصون من أعضاء هيئة التدريس بكليات التربية الرياضية

تخصص مناهج وتدريس التربية الرياضية.

r- معلمي التربية الرياضية بمحافظة الوادي الجديد.

r- مديري المدارس بمرحلتي التعليم الإعدادي والثانوي بالوادي الجديد.

ع- موجهي مادة التربية الرياضية بمحافظة الوادي الجديد.

جدول (1)

توصيف مجتمع الاراسة

\begin{tabular}{|c|c|}
\hline العدد العد & أفراد مجتمع الدراسة \\
\hline$r$. & خبراء في المناهج وتدريس التربية الرياضية \\
\hline 99 & معلم تربية رباضية \\
\hline$r \varepsilon$ & موجه تربية رباضية \\
\hline$\wedge_{7}$ & مدير مدرسة \\
\hline Trq & المجموع \\
\hline
\end{tabular}

عينة الاراسة:

1- الخبراء المتخصصين في مجال المناهج وتدريس مادة التربية الرياضية. r- معلمي التربية الرياضية بمحافظة الوادي الجديد.

r- مديري المدارس بمرحلتي التعليم الأساسي والثانوي بالوادي الجديد. ع- موجهي مادة التربية الرياضية بمحافظة الوادي الجديد.

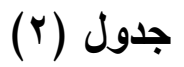

توزيع المعلمين والموجهين ومديري المدارس عينة الدراسة على الإدارات التعليمية

\begin{tabular}{|c|c|c|c|c|c|c|}
\hline \multicolumn{2}{|c|}{ مدبر مدربنة } & \multicolumn{2}{|c|}{ موجه } & \multicolumn{2}{|c|}{ مهلم } & \multirow[t]{2}{*}{ الإدارة التعلبهبة } \\
\hline نانومي & إعدادهي & نانـوي & إعدادمي & نانويمي & إعدادهي & \\
\hline$\varepsilon$ & 10 & 1 & r & V & 10 & إدارة الخارجة التعليمية \\
\hline r & V & 1 & 9 & 0 & 14 & إدارة الداخلة التعليمية \\
\hline
\end{tabular}




\begin{tabular}{|c|c|c|c|c|c|c|}
\hline 1 & 0 & - & 1 & 1 & $\Lambda$ & إدارة الفرافرة التعليمية \\
\hline 1 & $\varepsilon$ & 1 & - & $r$ & 1 & إدارة باريس التعليمية \\
\hline 1 & $\varepsilon$ & - & 1 & $r$ & r & إدارة بلاط التعليمية \\
\hline 1. & ro & $r$ & $1 \varepsilon$ & $1 \mathrm{~V}$ & rq & المجموع الكلى 11 11 \\
\hline$\% \wedge, 0$ & \%r. & $\% r, 0$ & $\% 1 r$ & $\% 1 \leq$ & אח & النسبة المئوية \\
\hline
\end{tabular}

أدوات جمع البيانات:

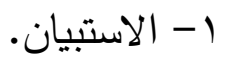

r- ب المقابلة الشخصية

r- استطلاع رأى الخبراء.

أدوات الاراسة:

تم إعداد أربعة أدوات للدراسة يمكن توضيحها علي النحو التالي:

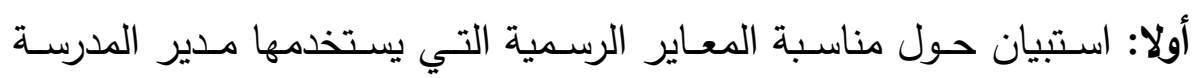

(سنويا) في تقييم أداء المعلمين من وجهة نظر معلم التربية الرياضية.

ثانيا: مقابلة مع مديري مدارس محافظة الوادي الجديد (عينة الدراسـة) لمعرفة وحية الأسـاليب والأدوات التي يستخدمها كل منهم عند تقيريم الأداء المهني لمعلمي التربية الرياضية.

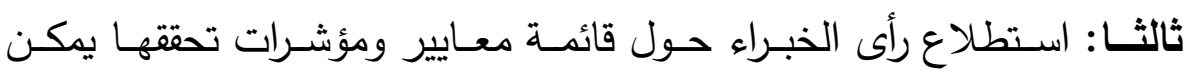

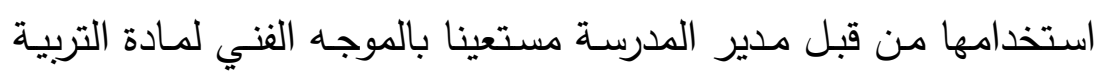
الرياضية عند تقييم الأداء المهني لمعلمي التربية الرياضية.

المعاملات العلمية لأدوات الدراسة:

أولا: استبيان حول مناسبة المعاير الرسمية التي يستخدمها مدير المدرسة سنويا في تقييم أداء المعلمين من وجهة نظر معلم التربية الرياضية.

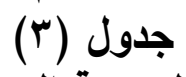

استبيان حول مناسبة المعاير الرسمية التي يستخدمها مدير المدرسة عند

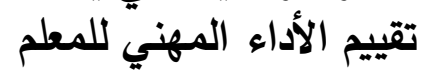


○人

\begin{tabular}{|c|c|c|c|c|}
\hline منابن & مناسب & مناسب & المعابيبر المستنفدمة سنويا & رقمعيار \\
\hline & & & 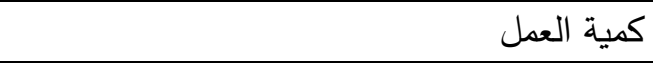 & 1 \\
\hline & & & درجة إتقان العمل & $r$ \\
\hline & & & درجة مشاركته في تحسين مستوى أداء العمل بالمدرسة & r \\
\hline & & & نتائج تقويم أداء تلاميذ المعلم & $\varepsilon$ \\
\hline & & & الشهادات والدرجات العلمية والدورات التدريبية & 0 \\
\hline & & & سلوكيات المعلم مع التلاميذ وإدارة المدرسة & 7 \\
\hline & & & الانضباط في العمل & $V$ \\
\hline \multicolumn{5}{|c|}{ أسئلة مفتوحة الإجابة } \\
\hline \multicolumn{3}{|c|}{ إجابات غير مقيدة } & 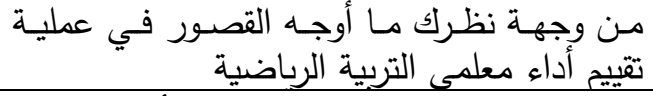 & أولا \\
\hline \multicolumn{3}{|c|}{ إجابات غير مقيدة } & لمعلمى التربية الرياضينية عمليـة تقيـيم الأداء المهني & ثانيا \\
\hline
\end{tabular}

وتم إعداده من خلال إتباع الخطوات التالية:

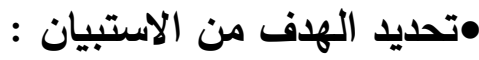

هـدف هـذا الاسـتبيان إلـي تحديـــ مـدى قبـول واقتنـاع معلمسي التربيـة

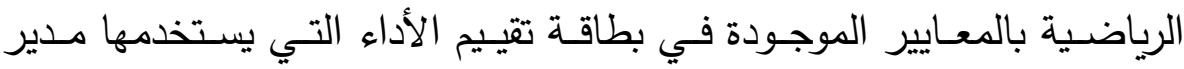

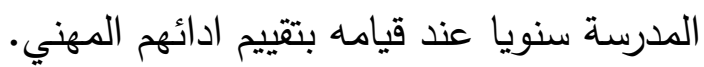

• مصادر إعداد الاستبيان:

اعتمدت الدراسة الحالية في إعداد الاستبيان علي المصادر التالية:

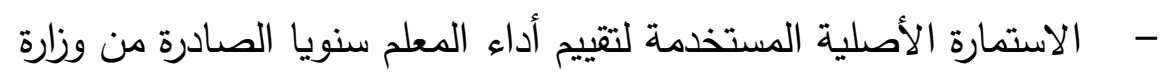

التربية والتعليم.

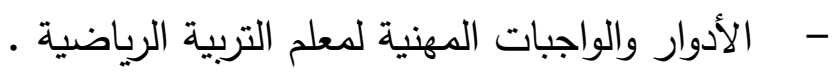

- - المعايير القومية للتعليم في مصر التي وضعتها وزارة التربية والتعليم

$\cdot r$

مجلة أسيوط لعلوم وفنون التربية الرياضية 
- - الأدبيات التربوية الحديثة، وآراء الخبراء والمتخصصين وأساتذة الجامعات في مجال تدريس مادة التربية الرياضية. : أبعاد الاستبيان :

تكونت أبعاد الاستبيان من المعايير الموجودة فعليا في استمارة تقييم

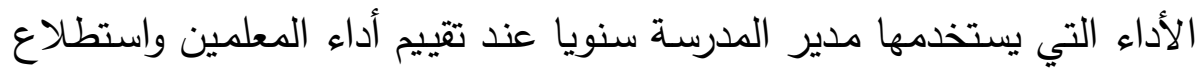

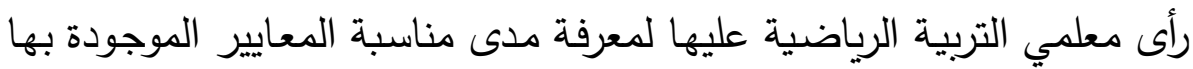
لقياس أدائهم المهني. طريقة الاستجابة للاستبيان:

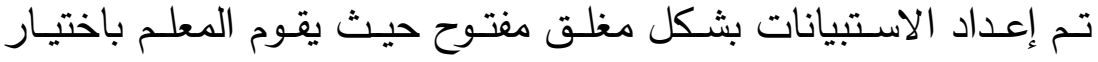
الإجابة المناسبة من بين الإجابات المعطاة (مناسب، مناسب إلى حد ما، غير

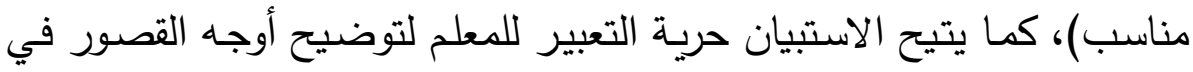

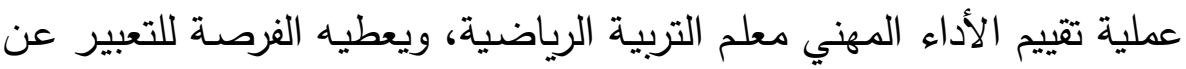

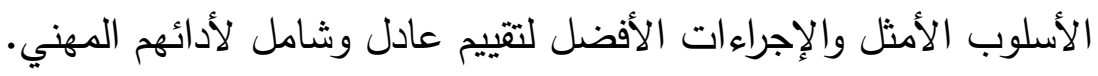

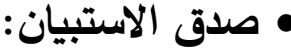

التزم الباحث باستخدام المعايير الرسمية المستخدمة دون تغير في الجزء

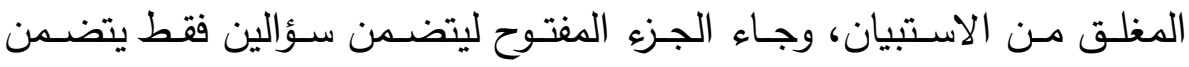
احدهما أوجه النقد، والأخر يستطلع المقترحات، واكتفى الباحث بتوجيهات هيئة

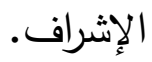

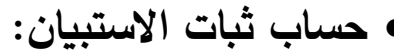

تم إعادة عرض الاستبيان علي خمسة عشر من معلمي التربية الرياضية

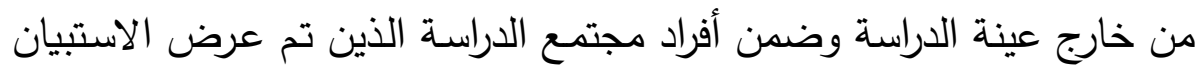

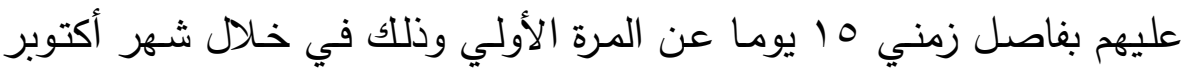
17 ـ ـ זم، والجدول التالي يوضح نسب الاتفاق.

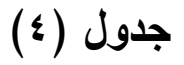


نسب اتفاق المعلمين حول المعاييز المستخدمة من قبل مدير المدرسة(ن= 0 1)

\begin{tabular}{|c|c|c|}
\hline الانونازة نسبة & المعابير المسيتنهدمة سنـوبا & رقمثيار \\
\hline$\% \wedge \vee$ & كمية العمل & 1 \\
\hline$\% 1 \ldots$ & درجة إتقان العمل & r \\
\hline$\% \wedge \vee$ & درجة مشاركته في تحسين مستوى أداء العمل بالمدرسة & r \\
\hline$\% 1 \ldots$ & نتائج تقويم أداء تلاميذ المعلم & $\varepsilon$ \\
\hline$\% \wedge \vee$ & الثهادات والدرجات العلمية والدورات التدرببية & 0 \\
\hline$\% 1 \ldots$ & سلوكيات المعلم مع التلاميذ وادارة المدرسة & 7 \\
\hline$\% \wedge \vee$ & الانضباط في العمل & V \\
\hline$\% 94$ & \multicolumn{2}{|l|}{ النسبة المئوية للثبات الكلي لجميع المعايير الموجودة بالاستبيان } \\
\hline
\end{tabular}

ثانيا: مقابلة مـ مديري مدارس محافظة الوادي الجديد (عينة الدراسـة) لمعرفة الأسـاليب والأدوات التي يستخدمها كل منهم عند تقييم الأداء المهني لمعلمي التربية الرياضية.

\section{ه تحديد الكهف من بطاقة المقابلة :}

هدفت بطاقة المقابلة إلي تحديد ومعرفة الأسس التي يرتكز عليها مديري المدارس عند تقييمهم لـلأداء المهني لمعلمي التربية الرياضسية وكذلك معرفة الأسـاليب والإجـراءات المتبعـة عنـد الثـروع في عمليـة تقيـيم الأداء المهنـي لمعلمي التربية الرباضية. صدق بطاقة المقابلة .

تم استخدام صدق المحكمين حيث تم عرض بطاقة المقابلة علي خمسة مـن المحكمين المتخصصين في مجال المنـاهج وتدريس التربيـة الرياضـية، وكانت آراء المحكمين إيجابية تجـاه بطاقة المقابلـة باستثناء بعض التعديلات بخصوص صياغة بعض الأسئلة، وتم تعديل صسياغة هذه الأسئلة وفقا لآراء المحكمين. القيام بعملية المقابلة. 
بعد تحديد عينـة الدراسـة كما سبق الإشـارة إليها قام الباحث بزيـارة (0؛ مدير مدرسة) وفق خطة زمنية معدة لذلك، واجري المقابلة مع السادة المدرين، وسجل النتائج، ووجه لـهم الشكر لتعاونهم.

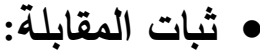

ولثبات المقابلة تم عمل مقابلة لعدد( • (1) مدير مدرسـة من خارج عينـة

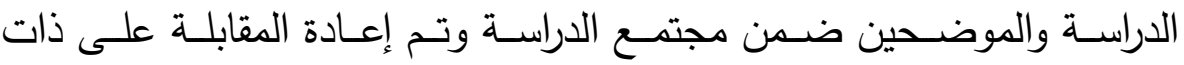
المجموعـة بعـد مـرور خمسـة عشـر يومـا مـن إجـراء المقابلـة والجدول التـالي يوضح نسب ثبات المقابلة، والجدول التالي يوضح نسب الاتفاق

$$
\text { جدول (0) }
$$

نسب الاتفاق لاستجابات المديرين على أسئلة المقابلة (ن= ()

\begin{tabular}{|c|c|c|}
\hline المئوبية & الإجابات & أسئلة المقابلة \\
\hline$\% 1 \ldots$ & الرياضية & 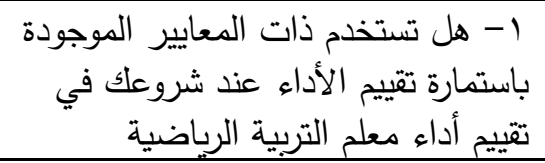 \\
\hline$\% q$. & 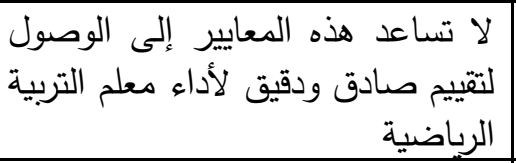 & 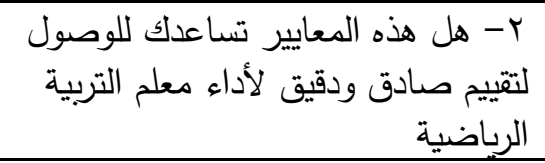 \\
\hline$\% 1 \ldots$ & إدارية بخصوص ليصلي كتب دورية أو نشرات & 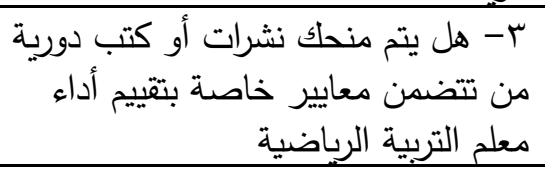 \\
\hline$\% 9$. & الإلتزامة بمواعيد العمل والتكليفات & بكمية العمل تقدر درجة المعيار الخاص \\
\hline
\end{tabular}

$$
\text { تابع جدول (•) }
$$

\begin{tabular}{|c|c|c|}
\hline$\% 1 \cdot \bullet$ & ملاحظة أداء المعلم & 0- كيف تقاصدر درجة المعيار \\
\hline
\end{tabular}

نسب الاتفاق لاستجابات المديرين على أسئلة المقابلة (ن= • ( )

\section{مجلة أسيوط لعلوم وفنون التربية الرياضية}




\begin{tabular}{|c|c|c|}
\hline$\% 9$. & الرياضية والتزامهة التلاميذ في حصية الرياضي التربية & 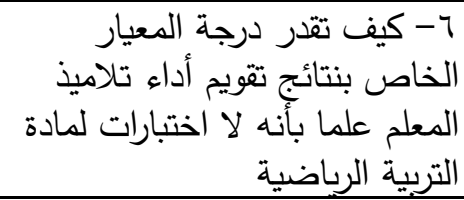 \\
\hline$\% 9$. & يستدعى إليها & 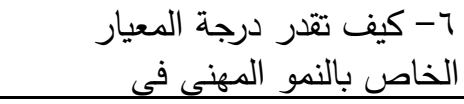 \\
\hline$\% 1 \ldots$ & المعم أراجعها قبل الشروع في تقييم الأداء & 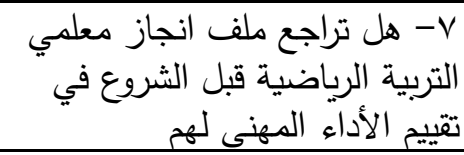 \\
\hline$\% 1 \ldots$ & 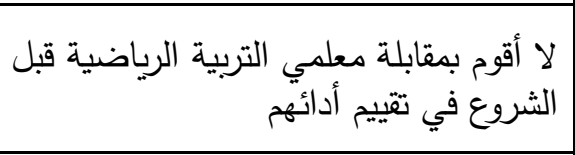 & 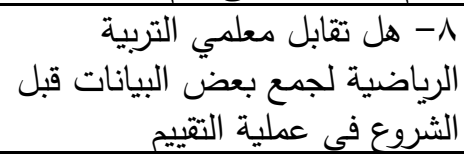 \\
\hline$\% 1 \ldots$ & لا أراجع سجل الزيارات قبل التقييم مباشرا & 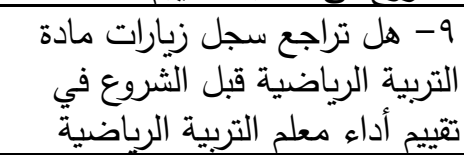 \\
\hline$\% 1 \ldots$ & 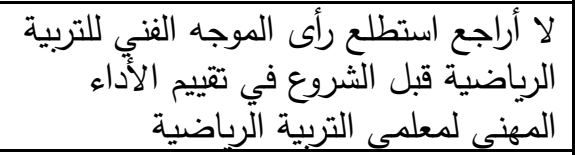 & 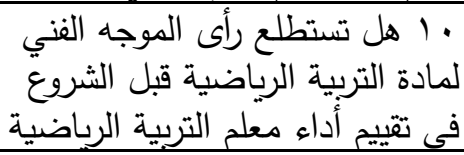 \\
\hline$\% 1 \ldots$ & لاحظاتيم على مدار التعام الدراسي لكن أسجل & 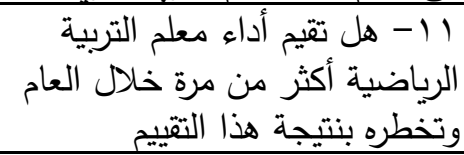 \\
\hline$\% \wedge$. & أقيم بنفسي جميع المعلمين & الرباضية الهل تقيم بنفسك معلم التربية \\
\hline$\% 9$. & امتيازا ويستحقون ذلك & 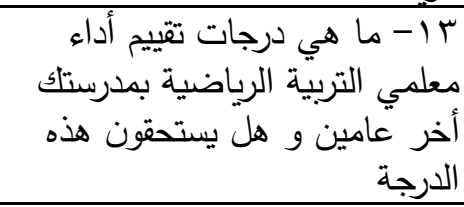 \\
\hline$\% 90$ & لعامة للاتفاق & 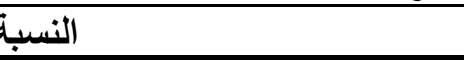 \\
\hline
\end{tabular}

ثالثـا: اسـتطلاع رأى الخبـراء حـول قائمسـة معـايير ومؤشـرات تحققهـا يمكن استخدامها من قبل مدير المدرسـة مستعينا بالموجهه الفني لمادة التربية الرياضية عند تقييم الأداء المهني لمعلمي التربية الرباضية.

جدول (7)

\section{مجلة أسيوط لعلوم وفنون التربية الرياضية}




\section{قائمة المعايير المقترحة}

\begin{tabular}{|c|c|}
\hline المعابير & المجال \\
\hline يلتزم بأوقات العمل الرسمي & \multirow{2}{*}{ الإلتـزام بأوقـات العــل لـرســـي والتكليفـات } \\
\hline يلتزم بالتكليفات الإدارية & \\
\hline يلتزم بأخلاقيات مهنة التعليم & \multirow[t]{2}{*}{ الالتزام بأخلاقيات المهنة - علاقات العمل } \\
\hline العملية التعليمية على علاقات جيدة مع أطراف & \\
\hline يحــرص علــى الــتعلم والنمــو المهنــي & \multirow[t]{2}{*}{ طلاب المعلم والنمـو المهني المستمر - مستوى أداء } \\
\hline مستوى أداء و تحصيل طلاب المعلم & \\
\hline بلم بالتربية الرحتوى والأنشطة والمفاهيم المرتبطة & \multirow[t]{2}{*}{ 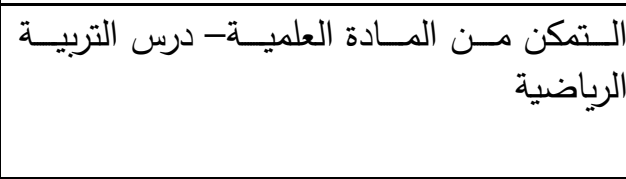 } \\
\hline ينفذ درس التربية الرباضية بشكل علمي & \\
\hline يفعـلـل الأنثــــة الرياضـــية والكثـــية & \multirow[t]{2}{*}{ تفتئج الفرق الأنشـطـة الرياضية } \\
\hline تظهـر الفـرق الرياضــية بمسـتوى جيــد & \\
\hline
\end{tabular}

لوضع قائمة المعايير اطلع الباحث على المصادر الآتية:

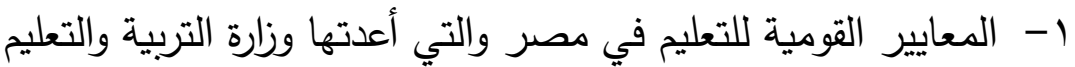
بصر عام r.. بام.

r- المعايير القومية الأردنية لتتمية الدعلم مهنيا والتي وضعتها وزارة التربية

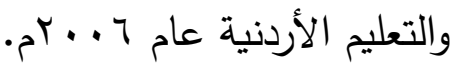

r- المعايير الوطنية المهنية للمعلمين وقادة المدارس في قطر التئي أعدها المجلس القومي للتعليم في قطر ك +. rم.

ع- معايير عناصر العملية التربوية في المملكة العربية السعودية والتي أعدتها وزارة التربية والتعليم في المملكة عام ^ .. بام. 
ه- الإطار الاسترشادي للمعلم العربي الذي أصدرته الأمانة العامة لجامعة الدول العربية إدارة التربية والتعليم والدراسة العلمي عام ^ . . بم. 7- معايير معلم التربية البدنية بالمملكة العربية السعودية عام با ـ بم. - الدراسات والرسائل العلمية التي تعرضت لمعايير معلم التربية الرياضية. - - توجيهات السادة الخبراء بالمناهج وتدريس التربية الرياضية. • الصدق الظاهري لقائمة المعايير:

للتحقق مـن الصدق الظـاهري للقائمـة تم عرضـها على مجموعـة من الخبراء المختصين في مجال تدريس التربية الرياضية وذللك للتأكد من وضوحها وملائمسة صياغتها وسـلامة لغتها، واستفاد الباحث من اتفاق (0) من الخبراء حول تعديل بعض المعايير وإضـافة مؤشرات جديدة وحذف بعض المؤشرات وتعديل صياغة بعض المؤشرات الأخرى إلى أن وصلت لصورتها النهائية. • اتفاق الخبراء حول معايير القائمة: شارك عدد(· ·) من الخبراء المتخصصين في المناهج وتدريس التربية الرياضـية في إبـداء الـرأي حـول مـدى مناسـبة قائمسة المعـايير المقترحسة مـن الباحث، ومؤشرات تحقق هذه المعايير وجاءت النتائج كالأتي. 
جول جول جول (v)

النسب المئوية لاتفاق الخبراء حول قائمة المعايير المقترحة من الباحث

$(r \cdot=\dot{0})$

\begin{tabular}{|c|c|c|}
\hline الاتنفاقة & المعابي.ر & المجال \\
\hline \multirow[t]{2}{*}{$\% 1 \ldots$} & يلتزم بأوقات العمل الرسمى & \multirow{2}{*}{ 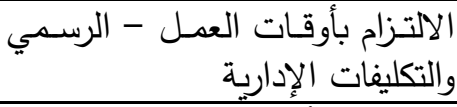 } \\
\hline & يلتزم بالتكليفات الإداربة & \\
\hline \multirow[t]{2}{*}{$\% 1 \ldots$} & يلتزم بأخلاقيات مهنة التعليم & \multirow{2}{*}{ 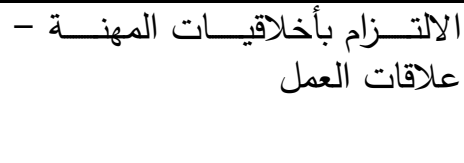 } \\
\hline & العملية التعليمية علاقات جيدة مع أطراف & \\
\hline \multirow[t]{2}{*}{$\% 1 \ldots$} & يحرص على التعلم والنمو المهنى المتسمر & \multirow{2}{*}{ التعلم والنمـو المهنـي المعلم المستمر - } \\
\hline & مستوى أداء و تحصيل طلاب المعلم & \\
\hline \multirow[t]{2}{*}{$\% 1 \ldots$} & بالتربية الرياضية والأنشطة والمفاهيم المرتبطة & \multirow[t]{2}{*}{ التربية الرياضنية مسنـادة العلميـة- درس } \\
\hline & ينفذ درس التربية الرباضية بشكل علمى & \\
\hline \multirow[t]{2}{*}{$\% 9 \wedge$} & يفعل الأنشطة الرياضية والكشفية اللاصفية & \multirow{2}{*}{ تفعيل الأنشطة اللاصفية - مستوى الفتائج الفرقية } \\
\hline & تظائج مرضية الفرق الرياضية بمستوى جيد وتحقق & \\
\hline$\% 99.7$ & \multicolumn{2}{|c|}{ النسبة العامة للاتفاق } \\
\hline
\end{tabular}

المعالجة الإحصائية:

للإجابة عن أسئلة الدراسـة استخدمت الدرجة المقدرة، النسبة المئوية لمعالجة البيانات. تحليل النتائج ومناقشتها: النتائج المتعلقة بالإجابة عن السؤال الأول: ما نقاط القوة والضعف في مقياس الأداء السنوي بشكله الحالي. 
جدول (^)

نتائج الاستبيان الموجه للمعلم حول المعايير المستخدمة سنوياً من قبل مدير

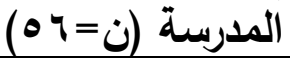

\begin{tabular}{|c|c|c|c|c|c|c|}
\hline المئوبيةة & المقدرةة & مناسبر & إلى هد ماسب & مناسب & المعايبير & النتقيتيات \\
\hline AY.AT & TH & $\wedge$ & $\wedge$ & $\varepsilon$. & 1- كمية العمل & \multirow{2}{*}{ أداء العامل } \\
\hline 19. $\mathrm{Yq}$ & ro. & $\varepsilon$ & V & $\leqslant 0$ & 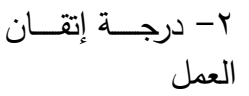 & \\
\hline $1 \ldots$ & rᄉ. & - & • & 07 & 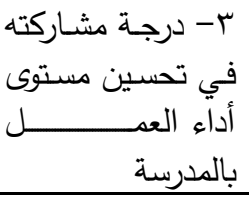 & \multirow{3}{*}{ الإدراكية } \\
\hline rq. rq & Ar & $\leqslant 0$ & $\varepsilon$ & 0 & أداء تـلاميذ المعلح & \\
\hline $9 . . \times 1$ & ros & 0 & r & $\varepsilon \wedge$ & 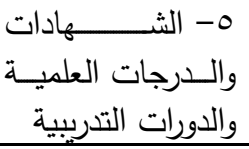 & \\
\hline $1 \ldots$ & r^. & - & - & 07 & 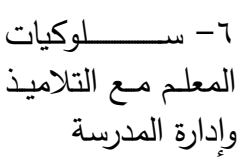 & \multirow{2}{*}{ السلوكية المهات } \\
\hline$V \varepsilon . r q$ & $r \cdot \Lambda$ & 1. & 17 & r. & 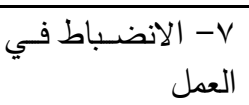 & \\
\hline $077 . \leqslant \varepsilon$ & 1017 & VY & rᄉ & rA. & \multicolumn{2}{|c|}{ المجموع } \\
\hline & $1 \cdot .9 r$ & & & & المتوسط العام & \\
\hline
\end{tabular}

بين الجدول (^) وجهة نظر معلمي التربية الرياضية في المعايير

الرسمية التي يلتزم مديري المدارس باستخدامها عند تقييم الأداء المهني لمعلمي التربية الرياضية سنويا وجاء إجماع آرائهم على المعيار (Y) الذي ينص على

درجة مشاركة المعلم في تحسين مستوى أداء العمل بالمدرسة، والمعيار (7) سلوكيات المعلم مع التلاميذ وإدارة المدرسة بنسبة ( (. (\%)، وبدرجة مقدرة

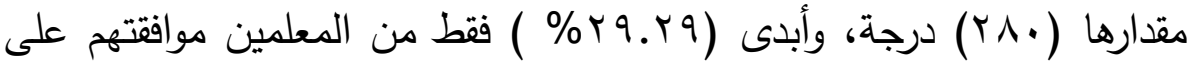
المعيار (ع) الذي نص على ربط تقييم أداء المعلم بنتائج تقويم أداء التلاميذ موني مجلة أسيوط لعلوم وفنون التربية الرياضية 
بدرجة مقدرة بلغت (YT) درجة يث لا اختبارات فعليه ورسمية لمادة التربية (V) الرياضية بالتعليم ما قبل الجامعي بمصر • وجاءت النسبة المئوية للمعيار

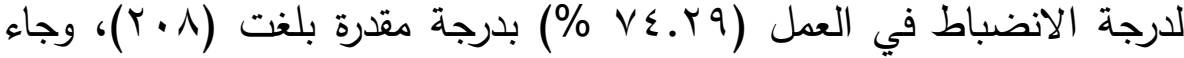
جدول (9)

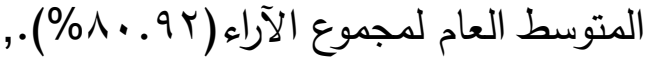

نقد عملية تقييم الألداء من وجهة نظر المعلم (ن= جول)

\begin{tabular}{|c|c|c|c|}
\hline المئوبة: النبة & التكرار & نقة & \\
\hline $1 \ldots \ldots$ & 07 & انفراد مدير المدرسة بتقدير أداء معلم التربية الرياضية دون غيره. & 1 \\
\hline VI. $\{r$ & $\varepsilon$. & التربية الرياضير عامـة لا يتتاسـب بعضــها لمتطلبـات العمـل المهنـي لمعلم & $r$ \\
\hline $1 \ldots$ & 07 & الكادرجـه كل لا يشـارك في تقية أعوام & r \\
\hline vo... & $\sum r$ & 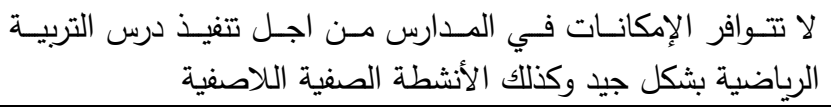 & $\varepsilon$ \\
\hline $77 . . V$ & rv & 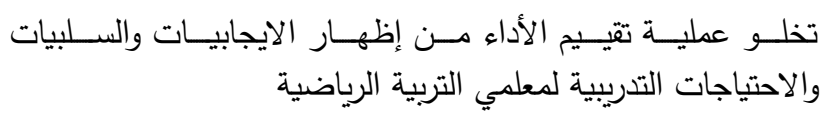 & 0 \\
\hline $7 r .0$. & ro & والتعلم الذاتي عملية تقييم الأداء معلمي التربية الرياضية بالتطور المهني & 7 \\
\hline 10.VI & $\varepsilon \wedge$ & لا لا توجد خطه واضحة محددة & V \\
\hline AV.०. & $\varepsilon 9$ & لا لإياضية مناهج واضحة أو دليل معلم يساعد في تنفيذ درس التربية & $\wedge$ \\
\hline 00.ru & T) & لا تفرق منظومة التقييم بين المعلم المتميز عن غيره & 9 \\
\hline VI.Vq & $\varepsilon r$ & لتيس هنـاك ربط بين كليـات التربيـة الرياضية والاتحـادات الرياضـية & 1 . \\
\hline \multicolumn{4}{|c|}{ 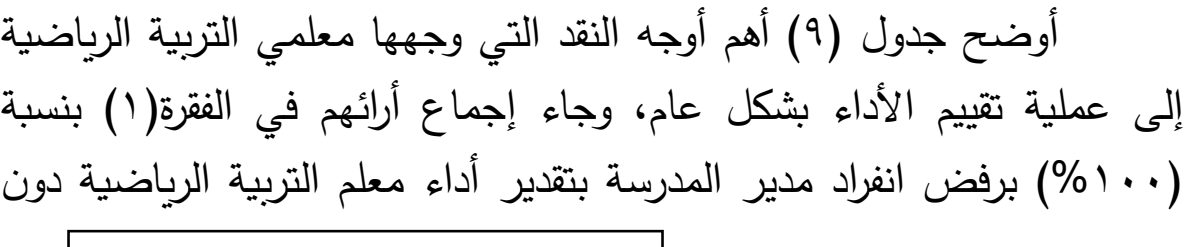 } \\
\hline & & 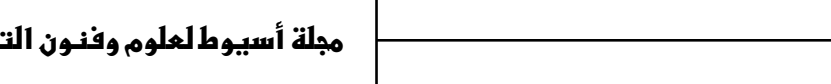 & \\
\hline
\end{tabular}


غيره. وبذات النتيجة (. (1\%) كان استيائهم من عدم إشراك الموجه الفني

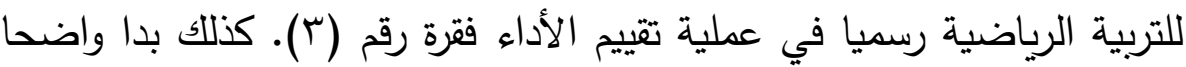

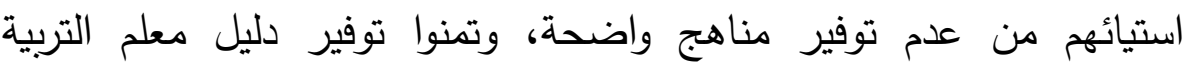

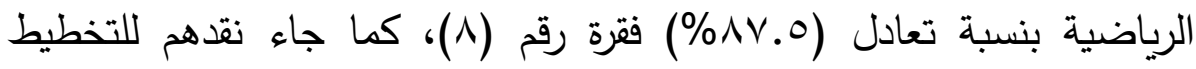

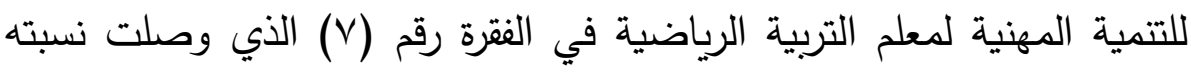

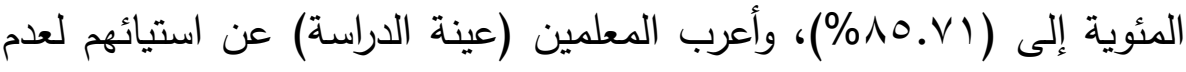

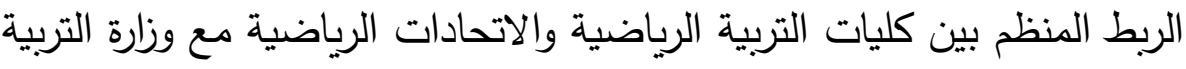

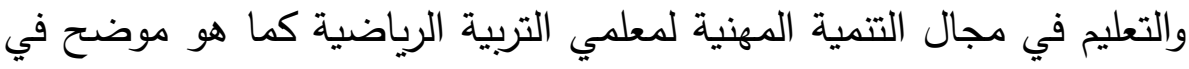
الفقرة رقم (• (1) حيث بلغة نسبة ذللك (VT.V9). وتظهر النتائج عدم اقتتاع المعلمين بانفراد مديري المداس بعملية تقييم

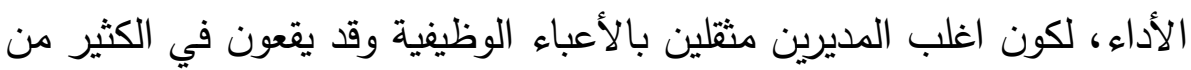
الأخطاء مثل التحيز أو التضضيل الشخصي. كما تشير النتائج إلى أن المقياس المستخدم في تقييز أداء معلم التربية

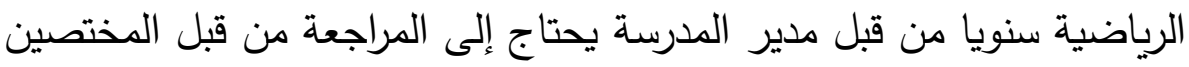

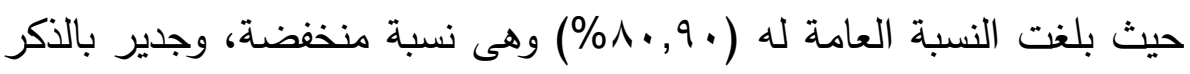

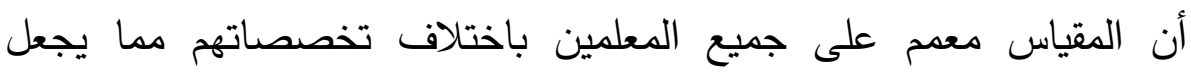
المقياس يفتقد الصدق. واظهر النتائج أيضا احتياج المقياس إلى التوضيح والتحديد وإعادة

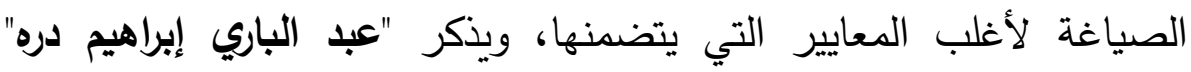

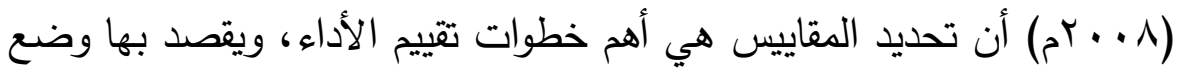

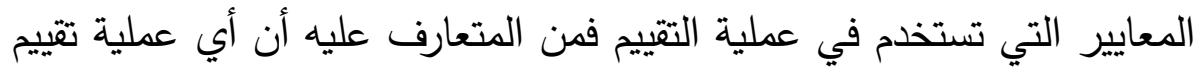

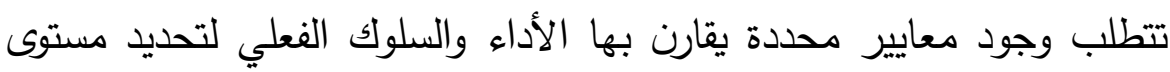

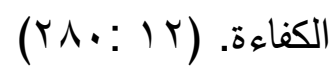

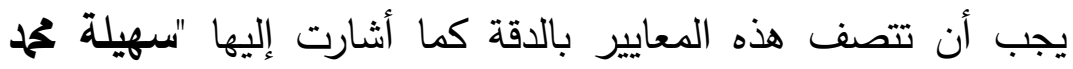

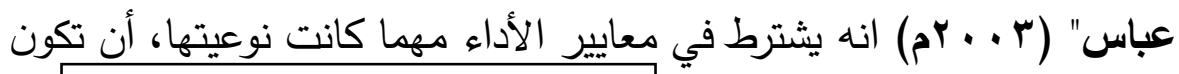
مجلة أسيوط لعلوم وفنون التربية الرياضية 
دقيقة في التعبير عن الأداء المراد قياسه و تقييمه، حتى تأتي المعلومات التي تعطيها هذه المقاييس على درجة عالية من الدقة و الفعالية. (9: بـ ( ) النتائج المتعلقة بالإجابة عن السؤال الثاني: ما الأساليب والأدوات التي يستخدمها مدير المدرسة عند تقييم الأداء المهني لمعلمي التربية الرياضية. جدول (1.)

نتائج المقابلة مع مديري المدارس لمعرفة كيف يقيمون الأداء المهني $(\varepsilon 0=\dot{0})$

\begin{tabular}{|c|c|c|c|}
\hline 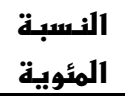 & 1ات:كرار & الإهابات & أَسئا1 المقابـة \\
\hline $1 \cdots$ & $\leqslant 0$ & لا لإياضية & 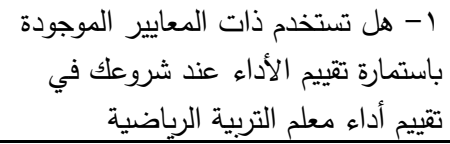 \\
\hline AY.rY & rV & 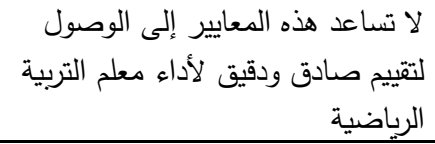 & التريّيم صادق ودقيق هذه المعايير تساءعاء معلى للوصول التربية \\
\hline $1 \ldots$ & $\leqslant 0$ & إدارية بخ يصلني كتب دورية أو نشرات & 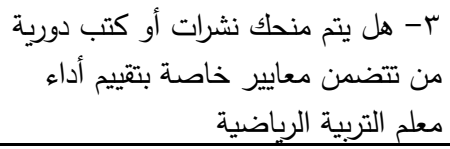 \\
\hline$\wedge \wedge . \wedge \wedge$ & $\varepsilon$. & 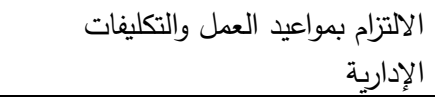 & ع بكمية العمل تقدر درجة المعيار الخاص \\
\hline$\wedge \varepsilon . \varepsilon \varepsilon$ & rᄉ & ملاحظة أداء المعلم & بإتقان العمل تقدر درجة المعيار الخاص \\
\hline 90.00 & $\varepsilon r$ & ملاحظة أداء التلاميذ في حصة التربية & 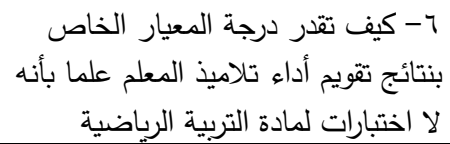 \\
\hline VV.VV & o r & $\begin{array}{r}\text { التي يستدره اجتماعات التوجيه والدورات إليهات }\end{array}$ & 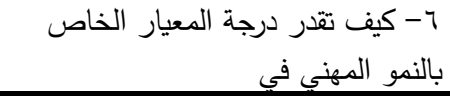 \\
\hline
\end{tabular}

\section{تابع جدول (1. - (1) - (1)}

\section{مجلة أسيوط لعلوم وفنون التربية الرياضية}


V.

نتائج المقابلة مع مديري المدارس لمعرفة كيف يقيمون الأداء المهني

$(\varepsilon \theta=\dot{0})$

\begin{tabular}{|c|c|c|c|}
\hline النئبسة & التكرار & 1إلإبات & أسئلة المقابـلة \\
\hline$\neg \wedge . \wedge \wedge$ & r & 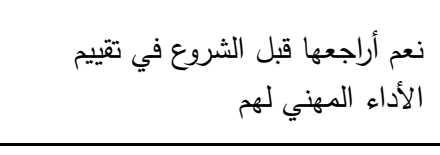 & 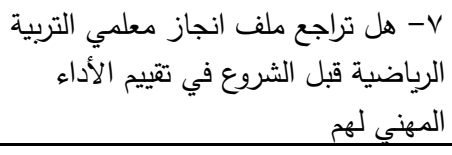 \\
\hline$\wedge \wedge . \wedge \wedge$ & $\varepsilon$. & 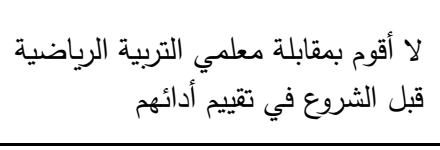 & لم- لجمع بعض تقابل معلمي التربية الرياضية \\
\hline V1.11 & rt & لا لأراجع سجل الزيارات قبل التقييم & الترباضية قبل تراجع سجل زيليارات مادة التربية \\
\hline מד.r. & $\leq r$ & للألتربية الرياضع استطلع رأى الموجه الفني الثروع في تقييم & ألتربية الرياضية قبل التسل الشروع في الموجه الفني لمادة \\
\hline$\wedge \varepsilon . \Sigma \varepsilon$ & rᄉ & لا لاحظييم أخر العام الدراسي لكن أسجل & أكثر من مرة التقييم خلال العام وتخطره بنتيجة أدراء معلم التربية الرياضية \\
\hline $1 \ldots$ & $\leq 0$ & أقيم بنفسي جميع المعلمين & 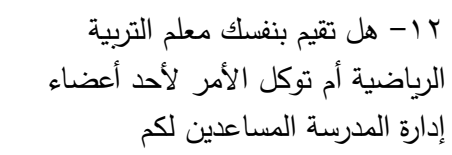 \\
\hline Nr.rt & rv & امتيازا ويستحقون ذللك & 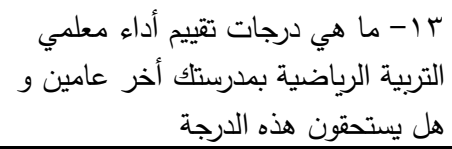 \\
\hline
\end{tabular}

يتضح من جدول ( · 1) انه اتفق الجميع بنسبة ( . . (1\%) على بعض

الإجابات منها يستخدمون المعايير الرسمية الموحدة في تقييم جميع المعلمين

ومن ضمنهم معلمي التربية الرياضية ، وبنفس النسبة اتفقوا على عدم منحهم

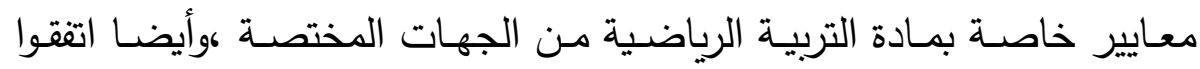

جميعا على أنهم يقيمون بأنفسه الأداء المهني لمعلمي التربية الرياضية سنويا

وعند الترقي.

\section{مجالة أسيوط لعلوم وفنوز الترببة الرياضية}


وبنسبة (rس.rq\%\%) لا يرجع المدير للموجهـ الفني للتربية الرياضية

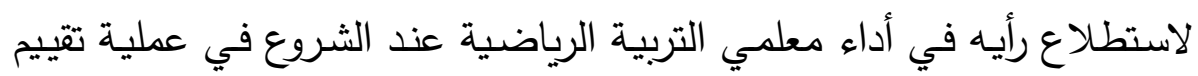

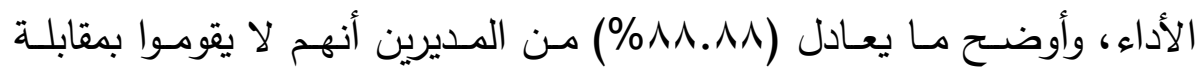

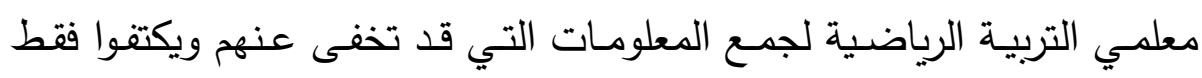

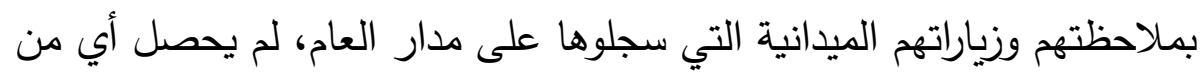

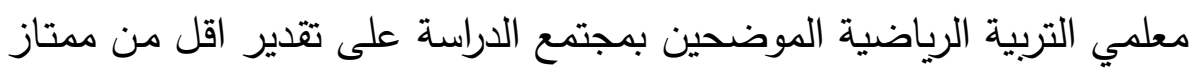

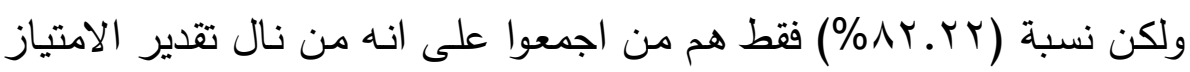

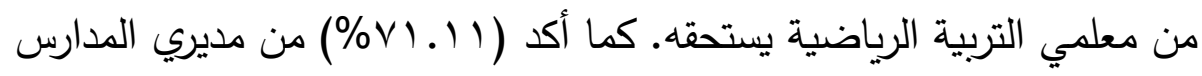

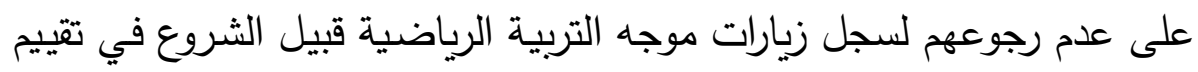
أداء معلم التربية الرياضية، فقط يكتفون بقراءتها والتوقيع عليها أثناء زيـارة

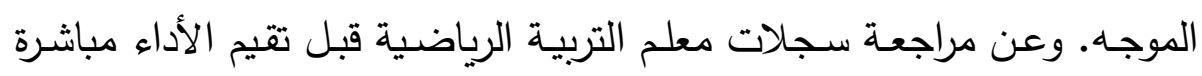

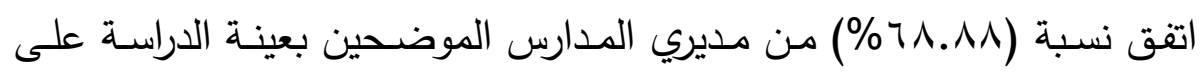

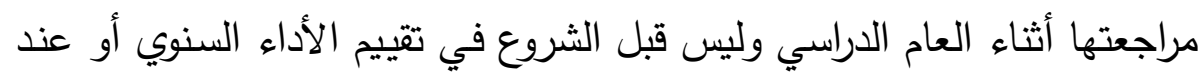

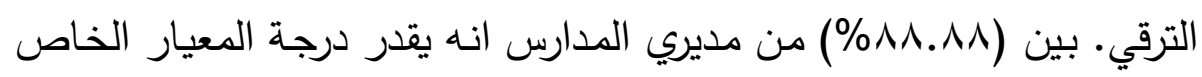

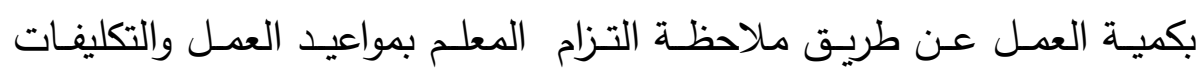

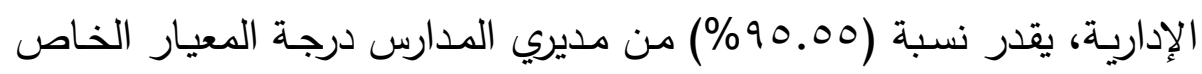

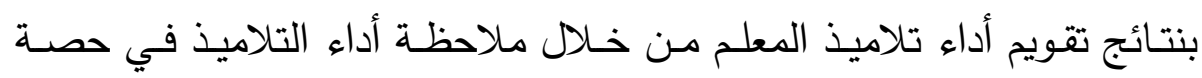

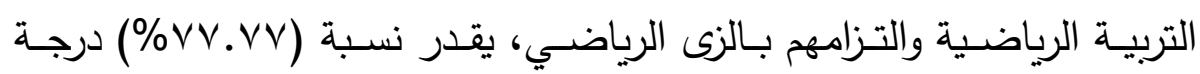

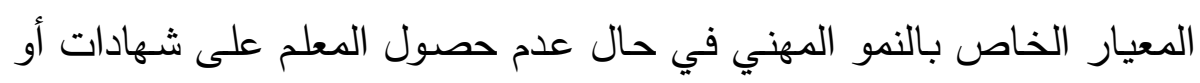

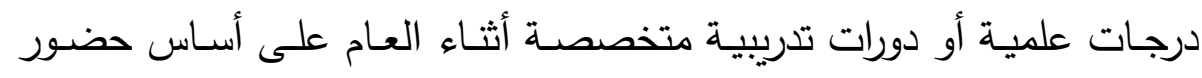

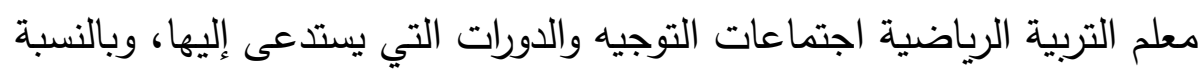

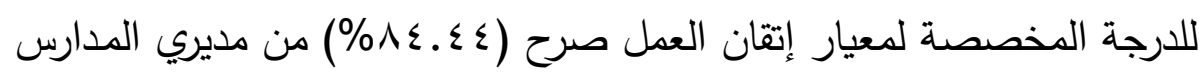
أنهم يستخدمون أسلوب الملاحظة المنظمة لتقدير درجة هذا المعيار . 
أظهرت النتائج أن جميع مديري المدارس يستخدمون المعايير الرسمية

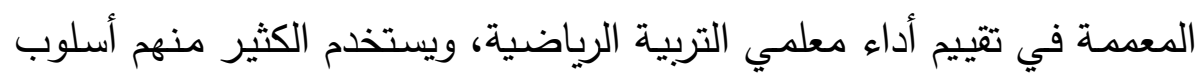

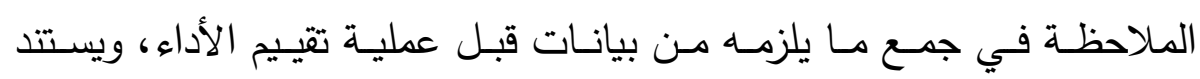
معظمهم إلى ما لديهج من خبرات في مجال الإدارة المدرسية للحكم على أداء

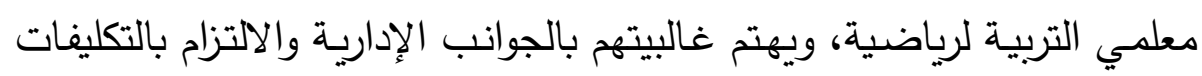

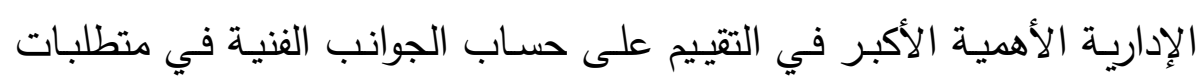
عمل معلم التربية الرياضية

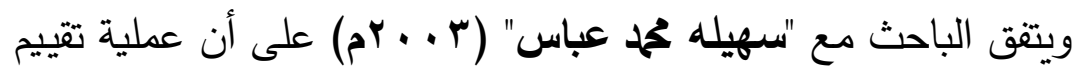

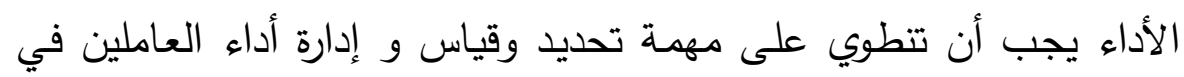

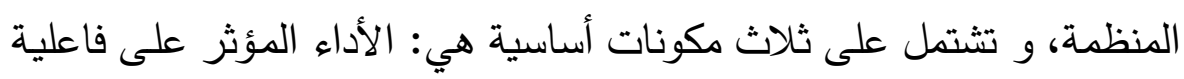

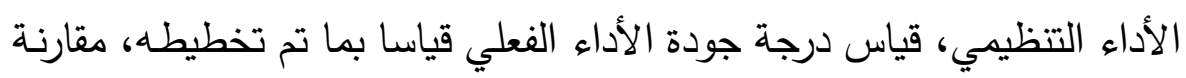

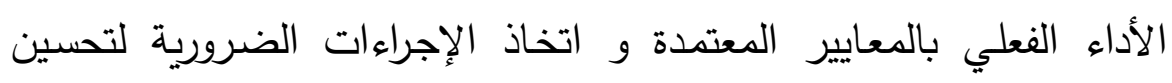

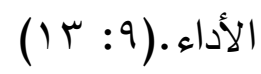

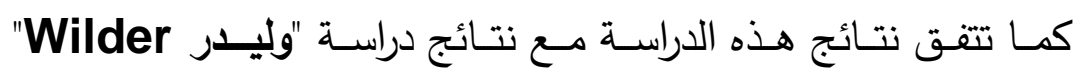

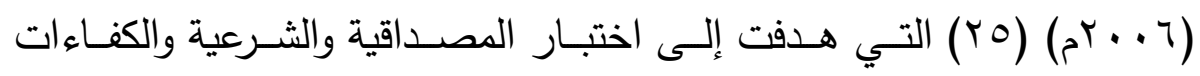

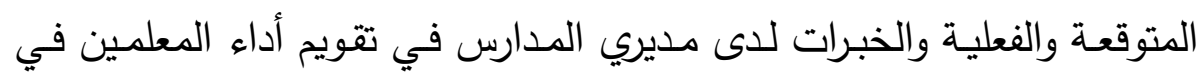
المدارس العالمية المعتمدة في شرق أسيا، والتعرف على الأساليب المتبعة في

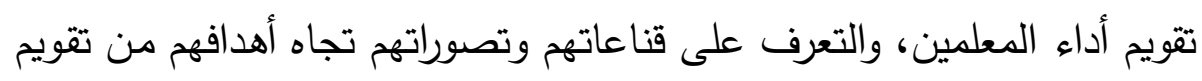

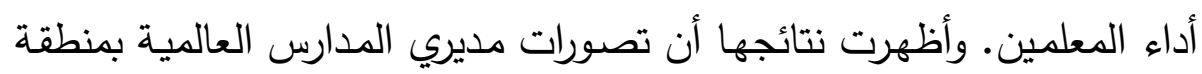

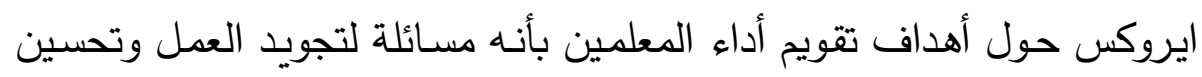

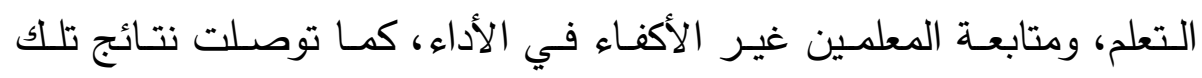

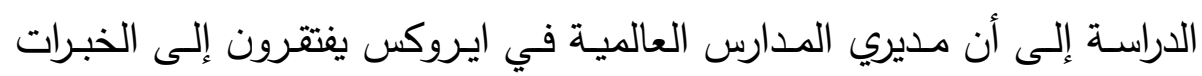

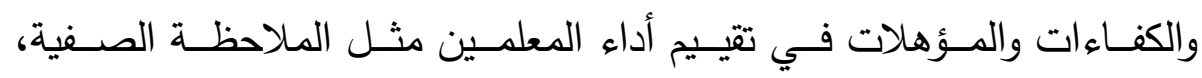


ويمارسون الأسـاليب الحديثة في التقويم بدرجة اقل، وأوصت الدراسـة بضرورة تدريب المديرين على مهارات تقويم أداء المعلمين. النتائج المتعلقة بالإجابة على السؤال الثالث: ما المعايير التي يمكن الاعتماد عليها في تقييم الأداء السنوي لمعلم التربية الرياضية. توصلت الدراسة إلى التوافق من قبل الخبراء المتخصصين في المناهج وتدريس التربية الرياضية حول قائمة من المعايير المقترحة من الباحث والتي يمكن استخدامها من قبل مدير المدرسة عند تقييم الأداء المهني لمعلمي التربية الرياضية حيث بلغت نسب الاتفاق(7.9.9) كما هو موضح بجدول (11)

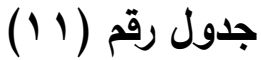
قائمة المعاييز المقترحة رقمة

\begin{tabular}{|c|c|c|c|c|}
\hline الاتنفاوبة\% & الـموَشْرات & المؤشَرات & المعابير & المجال \\
\hline \multirow[t]{2}{*}{$1 \cdots$} & \multirow[t]{2}{*}{$r$. } & 1. & يلتزم بأوقات العمل الرسمي & \multirow{2}{*}{ 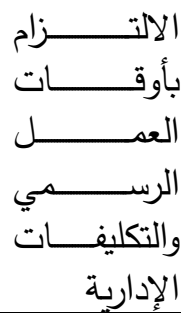 } \\
\hline & & 1. & يلتزم بالتكليفات الإدارية & \\
\hline \multirow[t]{2}{*}{$1 \ldots$} & \multirow[t]{2}{*}{$r \cdot$} & 1 . & يلتزم بأخلاقيات مهنة التعليم & \multirow{2}{*}{ 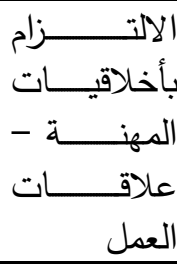 } \\
\hline & & $1 \cdot$ & أطراف العملية التعليمية جلاقات جيدة مع & \\
\hline \multirow[t]{2}{*}{$1 \ldots$} & \multirow[t]{2}{*}{$r \cdot$} & 1. & المتسرص على التعلم والنمو المهني & \multirow{2}{*}{ 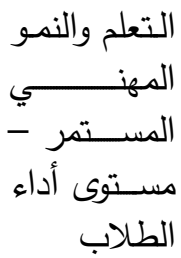 } \\
\hline & & $1 \cdot$ & مستوى تحصيل وأداء طلاب المعلم & \\
\hline
\end{tabular}

تابع جدول رقم (1) قائمة المعايير المقترحة رفية مجلة أسيوط لعلوم وفنون التربية الرياضية 


\begin{tabular}{|c|c|c|c|c|}
\hline 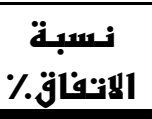 & المؤشمرات & المؤشثرات عدد & المعابير & المجال \\
\hline \multirow[t]{2}{*}{$1 \ldots$} & \multirow[t]{2}{*}{$r$. } & 1. & المرتبطة بالمحتوى والأنشطة والمفاهيم & \multirow{2}{*}{ 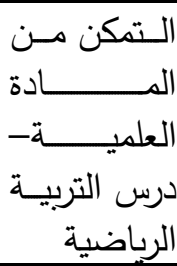 } \\
\hline & & 1. & علفيـذ درس التربيـة الرياضـية بشـل & \\
\hline \multirow[t]{2}{*}{91} & \multirow[t]{2}{*}{$r}$. & 1. & اللاصعـل الأنشــة الرياضـية والكثـفية & \multirow{2}{*}{ 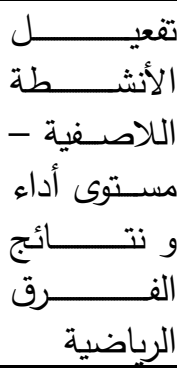 } \\
\hline & & 1. & تظتحقر الفرق الرياضية بمستوى جيد & \\
\hline 99.7 & مؤشرا & & عشرة معايير & المجموع \\
\hline
\end{tabular}

للمعايير أهمية كبيرة في تقييم أداء المعلم حيث يرى "كمال عبد الحميد زيتون" (ع + . Yم) أن المعايير" تلك العبارات التي يمكن من خلالها تحديد

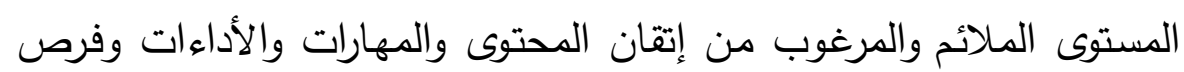
التعلم. (1) (1) (1) (

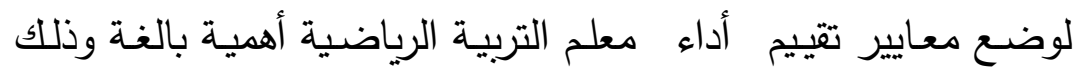
لإمكانية مقارنة الأداء بالمعايير المناسبة وما يترتب عليه من تعديل و تطوير

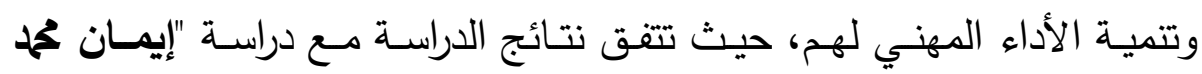
رمضان" (r ( • rم) (0) التي هدفت إلى: اقتراح المعايير التي يمكن الاعتماد عليها في تقييم أداء معلم التربية الرياضية في ضوء متطلبات الجودة والاعتماد في واقتراح مجموعة من المؤشرات التي يمكن إن تحقق كل معيار ، وتوصلت الدراسة إلى ضرورة تطبيق المعايير المقترحة على معلمي التربية الرياضية 


\section{vo}

بجمهورية مصر العربية نظرا للدور المهم الذي يقوم به في تتمية المجتمع بدنيا ونفسيا.

كما توصلت الدراسـة إلى الوصول إلى وضـع " تصـور مقترح لتقيسيم

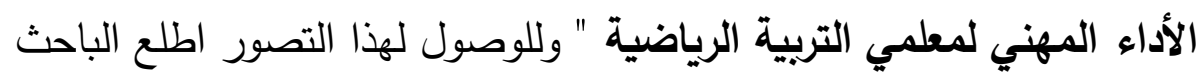
على بعض أدوات التقييم المستخدمة في بعض الدول العربية والموضحة بمرفق

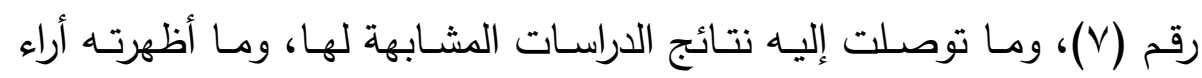
ومقترحات عينـة الدراسـة (معلم تربية رياضية - موجه تربية رياضية - مدير مدرسة) لتحسين عملية تقييم الأداء المهني لمعلمي التربية الرياضية والموضحة تربه

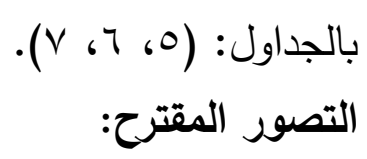

أولا: الرؤية العامة للتصور المقترح. ثانيا: أهداف التصور المقترح. ثالثا: أبعاد التصور المقترح. أهران رابعا: التصور المقترح. وسوف يتناول الباحث كلا مما سبق بالتنصيل كما يلي:

أولا الرؤية العامة للتصور المقترح: تنبثق هذا الرؤية من عدة عناصر على النحو التالي: ا- متطلبات مهنة معلم التربية الرياضية وما تتطلبه هذه المهنة من عن أعباء

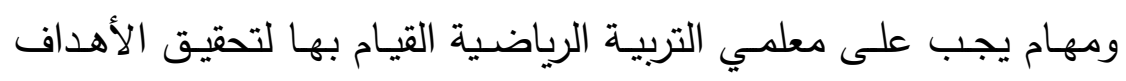
العامة والخاصة لمادة التربية الرياضية بمراحل التعليم المختلفة. r- دور الدراسـة العلمي في تشخيص المشكلات والإسهام في اقتراح الحلول المناسبة. 
r- طبيعة العلاقة التي تربط بين الدراسة العلمي والتتمية البشرية باعتبار أن

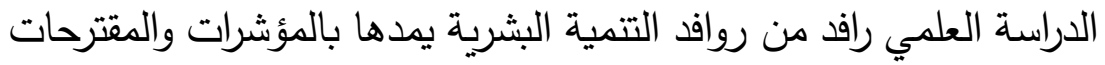

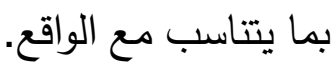

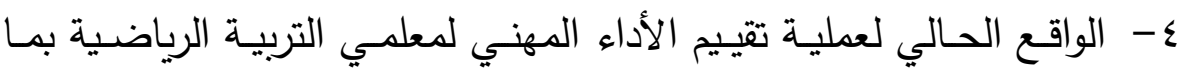
تحتويه من ايجابيات وسلبيات كما أوضحتها نتائج الدراسة.

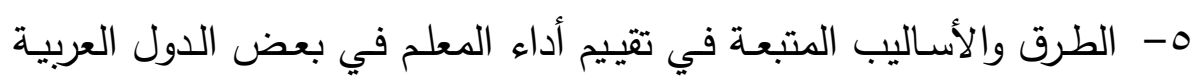
المهتمة بالتتمية البشرية.

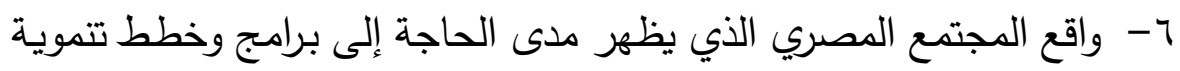

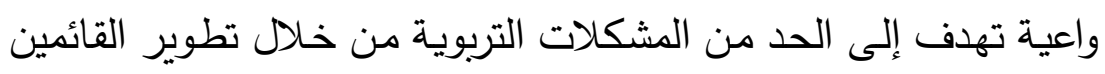
على العمل التربوي وعلى رأسهم المعلم.

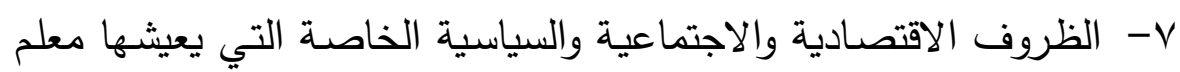
التربية الرياضية المصري مقارنة بزملائه في بلدان أخرى. ثانيا أهداف التصور المقترح : يهدف التصور المقترح إلى ما يلي: - - رفع قيمة توافر مؤشرات المعايير المهنية المعاصرة في أداء معلمي التربية

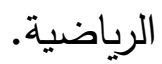

- - - تطوير أداء معلمي التربية الرياضية في ضوء معايير مهنية معاصرة.

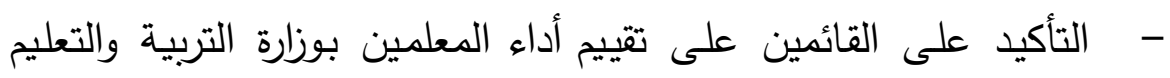

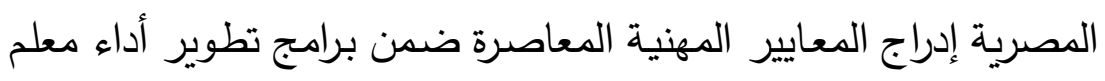
التربية الرياضية. - - التأكيد على القائمين على تقويم أداء المعلم المصري بوضع مقاييس أداء

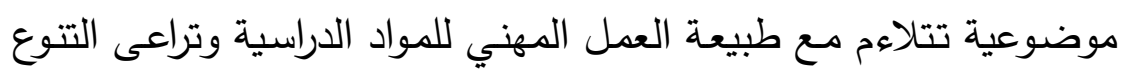
بين خصائصها. 
- توضـيح أهميـة مشـاركة الموجـه الفنـي فـي تقيـيم أداء معلمـي التربيـة الرياضية.

ثالثا ملامح التصور المقترح :

في ضوء النتائج التي توصلت إليها الدراسة وما توصلت إليه الدراسات المرتبطة والمشابهة لها يمكن تقديم ملامح التصور المقترح لتقييم الأداء المهني لمعلمي التربية الرياضية من خلال الأبعاد الأساسية التالية:

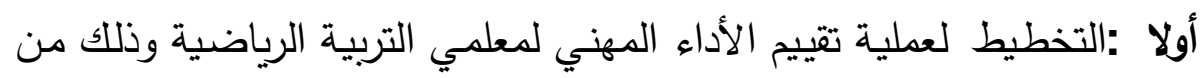

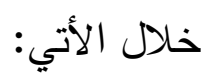
بدراسـة الواقع الفعلي ومعرفة مدى نقاط القوة والضعف في عملية تقييم

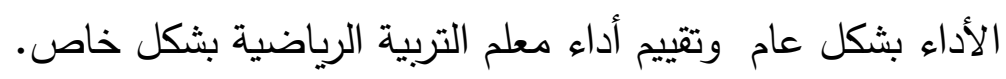

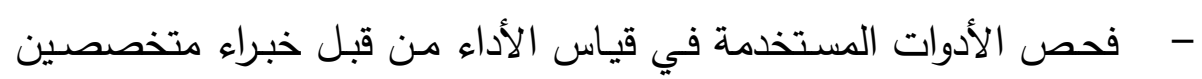
لمعرفة مدى ملأئمتها.

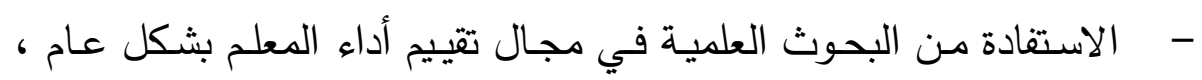
ومعلم التربية الرياضية بشكل خاص.

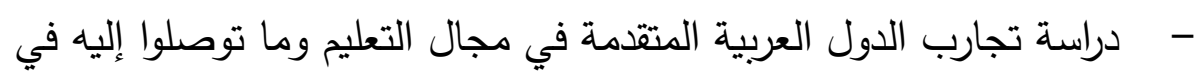
مجال تقييم الأداء المهني للمعلم بشكل عام، ومعلم التربية الرياضية بشكل خاص. - - الاهتمام بتوافر المعايير المهنية المعاصرة لمعلمي التربية الرياضية من

$$
\text { خلال البحوث العلمية بكليات التربية الرياضية }
$$

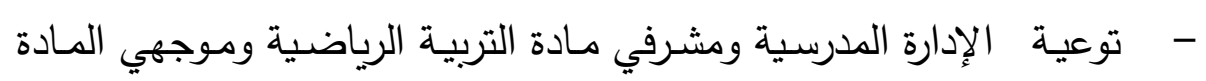
بالمعايير المهنية المعاصرة الخاصة بمعلمي التربية الرياضية. من خلال نشرات لتجارب عالمية وعربية، والتدريب على كيفية قياس الأداء واستخدام معايير تقييم الأداء. 
ثانيا: تطوير قدرات معلمي التربية الرياضية بوزارة التربية والتعليم المصرية.

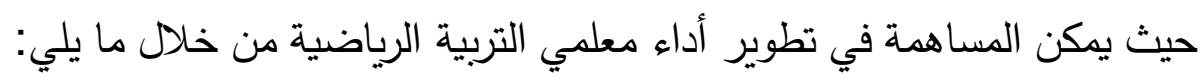

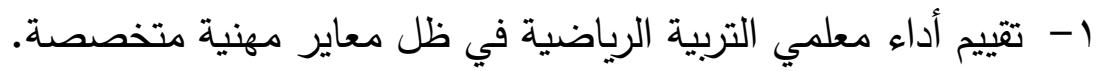

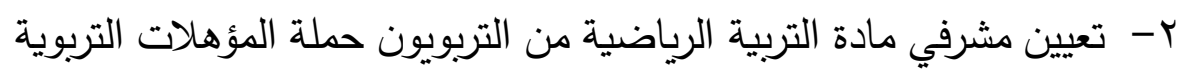

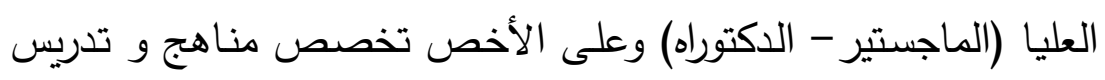
التربية الرياضية.

r- الإثراف على الدورات التدريبية لـعلمي التربية الرياضية من خلال متخصصين (خبراء من كليات التربية الرياضية بالجامعات المصرية).

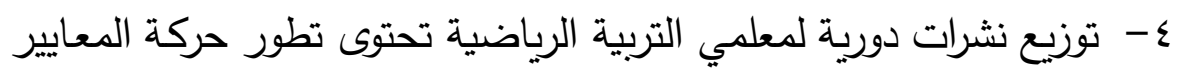
المهنية العالمية والعربية.

0- إعداد برامج علاجية للمعلمين تختص بتتمية المعايير التي يثبت وجودها

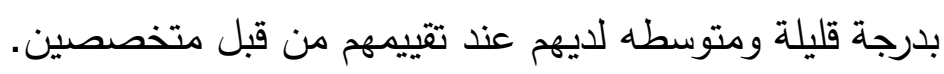
ثالثا: واجبات وزارة التربية والتعليم تجاه معلمي التربية الرياضية.

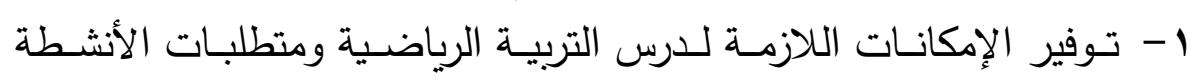
الصفية اللاصفية.

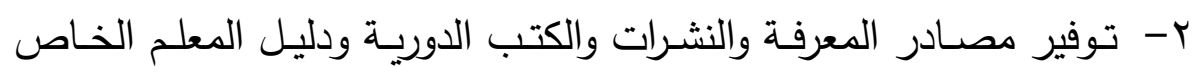
بمادة التربية الرياضية. r- التدريب والثقل المستمر لمعلمي التربية الرياضية على مستجدات المادة

$$
\text { وأساليب التدريس الحديثة. }
$$

ع - التشجيع والتحفيز المـادي والمعنوي للمتميزين من المعلدين ليكونوا قدوة لغيرهم من معلمي التربية الرياضية.

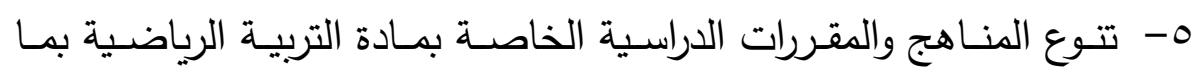

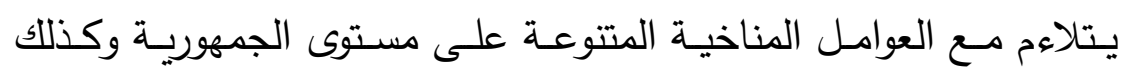


خصائص الطلاب وما يتوافر في المدارس من إمكانيات تمكن المعلم من تنفيذ المنهج وتحقيق أهدافه. رابعا: التصور المقترح لتقييم الأداء المهني لمعلمي التربية الرياضية.

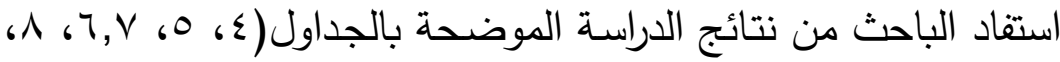
9، · ( ، (1)، والدراسات المشابهة لهذه الدراسة، وأراء الخبراء وتوجيهات هيئة الإشراف لوضع التصور المقترح ·

$$
\text { جدول (r) (1) }
$$

التصور المقترح لتقييم الأداء المهني لمعلمي التربية الرياضية

\begin{tabular}{|c|c|c|c|c|}
\hline الملاهظات & المقيم & الدقدرة & المعايير & م \\
\hline \multirow{5}{*}{ نقاط القوة: ............................ } & \multirow{5}{*}{$\begin{array}{l}7 \\
3 \\
\overline{3} \\
3 \\
3\end{array}$} & r. & يلتزم بأوقات العمل الرسمي & 1 \\
\hline & & 10 & يلتزم بالتكليفات الإدارية & r \\
\hline & & 10 & يلتزم بأخلاقيات مهنة التعليم & $r$ \\
\hline & & 1. & يحرص على علاقات جيدة مع أطراف العملية التعليمية & $\varepsilon$ \\
\hline & & 1. & يحرص على التعلم والنمو المهني المتسمر & $\bullet$ \\
\hline \multirow{5}{*}{ الاحتياجات التدريبية:................................. } & \multirow{5}{*}{ 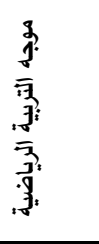 } & $\circ$ & مستوى تحصيل وأداء طلاب المعلم & 1 \\
\hline & & $\circ$ & يلم بالمحتوى والأنشطة والمفاهيم المرتبطة بالتربية الرياضية & $v$ \\
\hline & & $1 \cdot$ & ينفذ درس التربية الرياضية بشكل علمي & $\wedge$ \\
\hline & & 。 & يفعل الأنشطة الرياضية والكثفية اللاصفية & 9 \\
\hline & & $\circ$ & تظهر الفرق الرياضية بشكل جيد وتحقق نتائج مرضية & 1. \\
\hline \multicolumn{2}{|c|}{$\begin{array}{l}\text { مدير الإدارة التعليمية/الاعتماد } \\
\text { الإد }\end{array}$} & $1 \ldots$ & \multicolumn{2}{|l|}{ المجموع الكلى } \\
\hline \multicolumn{2}{|c|}{ 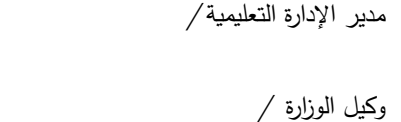 } & & \multicolumn{2}{|c|}{ موتير المدرسة/ } \\
\hline
\end{tabular}

يتضح من جدول (Y Y أن التصور المقترح يشتمل على معايير تغطى كافة جوانب العمل المهني لمعلمي التربية الرياضية، وتم توزيع الدرجات المقدرة لـتلاعم المعـايير بثـكل مناسـب، كمـا يثـارك موجـه التربيـة الرياضـية مـدير المدرسة في تقييم الأداء المهني لمعلمي التربية الرياضية فيما يتعلق بالمعايير

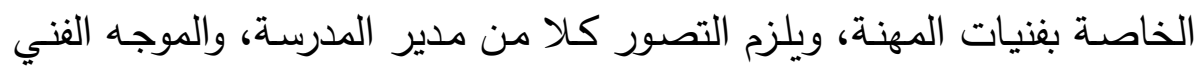

\section{مجلة أسيوطلعلوم وفنون التربية الرياضية}


توضيح النقاط الايجابية للاستفادة من قدرات المعلم المتميزة عند الاحتيـاج

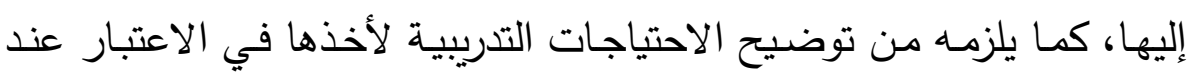

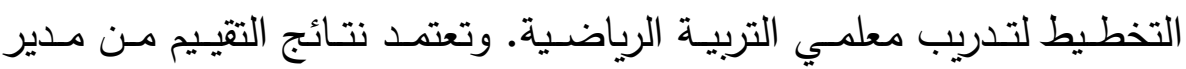
الدرسة، الموجه الفني، مدير الإدارة، وكيل وزارة التربية والتعليم.

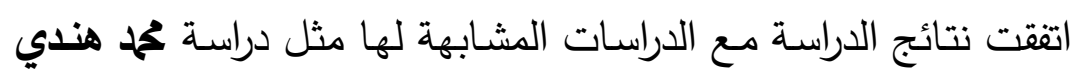

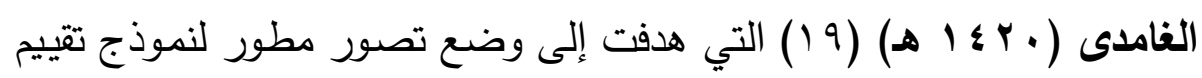

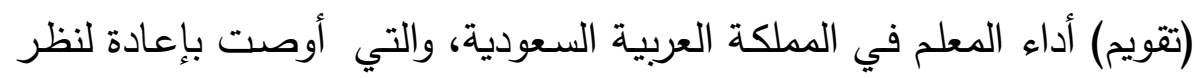

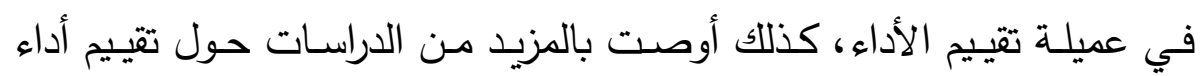

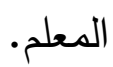

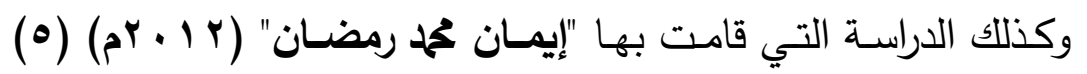

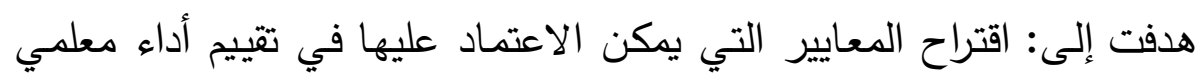

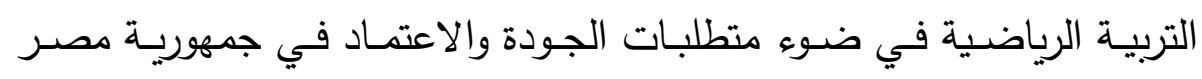

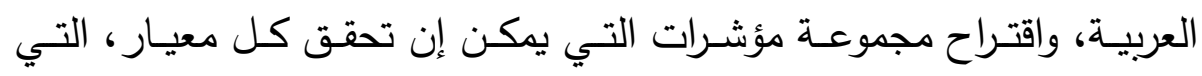
توصلت الدراسة إلى ضرورة تطبيق المعايير المقترحة على معلمي التربية الرياضية بجمهورية مصر العربية نظرا للدور المهم الذي يقوم به في تتمية فئية

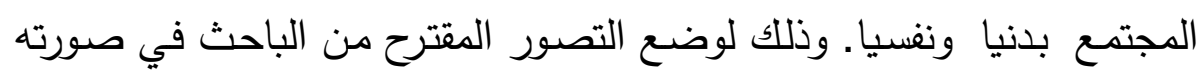
النهائية.

\section{$((2$}

\section{أولاً: المراجه العربية:}

1- أحمـــ إســماعيل حجـي: إدارة بيئسة التعلـيم والتتعلم والتعهـيم: النظريـة

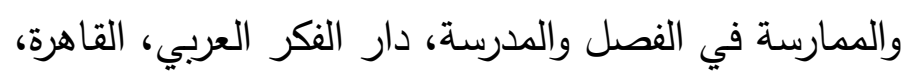

$$
\text { . }
$$


Y - أحمـد إســـاعيل حجـي: الإدارة التعليميـة والإدارة المدرسـية، دار الفكـر

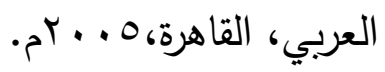

بـ - الجميـل تحمه شـعلة: التقـويم التربـوي للمنظومـة التعليميـة، دار الفكـر العربـي،

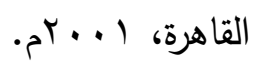

ع - إيمان احمد الجوفي: العلاقات الاجتماعية والنفسية الوظيفية وعلاقتها بالأداء الوظيفي، رسالة ماجستير غير منشورة، جامعة

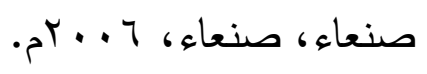

ه- إيمـان محمد رمضـان: معـايير مقترحسة لمعلم التربية الرياضـية في ضـوء متطلبات الجودة والاعتماد في التعليم، رسـالة دكتوراه غير منشـورة، كليـة التربيـة الرياضـية بنـين جامعـه الإسـكندرية،

$$
\cdot r^{2} \cdot 1 r
$$

צ- حازم زكى عيسى: تصور مقترح لتطوير الأداء التدريسي لمعلمي العلوم وفق معايير الجودة في المرحلة الأساسية بمحافظات غزة، مجلـة الجامعـة الإســلامية، المجلـد الثـامن عثـر ، العـدد

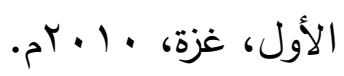

V- رضا إبراهيم المليجى: معجم المصطلحات في الإدارة التربوية والمدرسية،

$$
\text { دار الجامعة الجديدة، الإسكندرية، 11 } 1 \text { • م. }
$$

^- سعد عامر أبو شندى: إدارة الموارد البشرية في المؤسسات التعليمية، دار

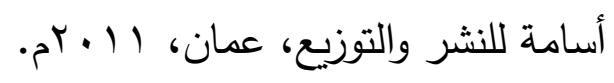

9- سهيلة محمد عباس : إدارة الموارد البشرية مدخل استراتيجي، دار وائل للنشر

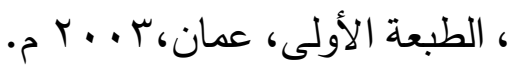


• 1- شــل بـدان الغريـب، وآخـرون: الثقافـة المدرسية ، دار الفكر للنشـر

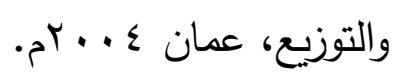

11- صـلاح الدين محمود عـلام: التقويم التربوي والنفسي دار الفكر العربي

$$
\text { القاهرة ، . . . ب م. }
$$

r ا - عبد الباري إبرا \يم دره، وآخرون: إدارة القوى البشرية،الثركة العربية

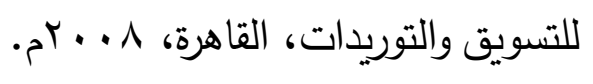

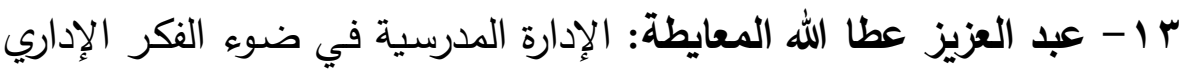

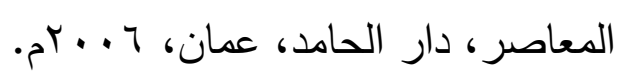

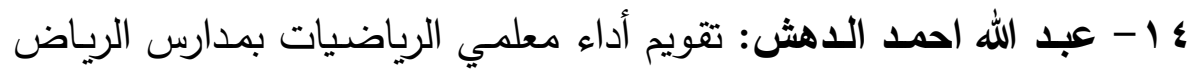

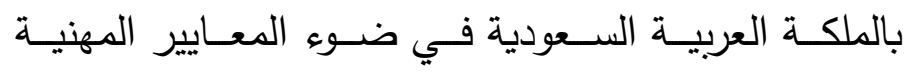

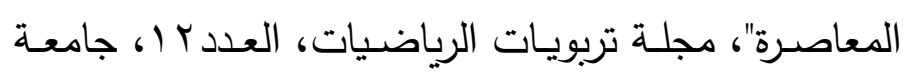

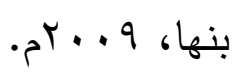

ه - عطاوى عـارف توفيق، وآخـرون: الإثـراف التربوي اتجاهاته النظريـة

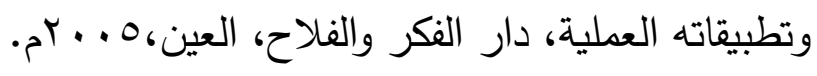

17 - عمر على دخلان: تقدير كفايات المعلم المساند من وجهه نظر مديري

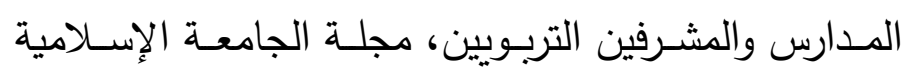

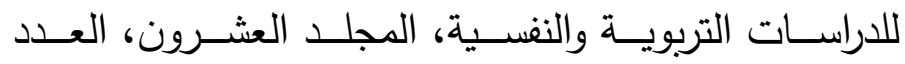

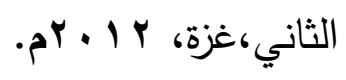

IV

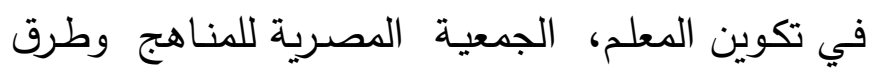

$$
\text { التدريس، جامعة عين شمس، القاهرة، ؟ . - بام. }
$$

\section{مجلة أسيوط لعلوم وفنون التربية الرياضية}


1 1 - محسـن لطفـي إبـراهيم: قيـاس الشخصـية، المصـرية الدوليـة للطباعـة

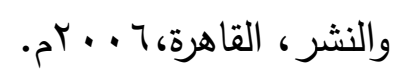

9 1 - عحمه هندي الغامدى : تصور مقترح لنموذج تقييم أداء المعلم في المملكة العربية السعودية، رسالة ماجستيرَ غير منشورة، قسم الإدارة

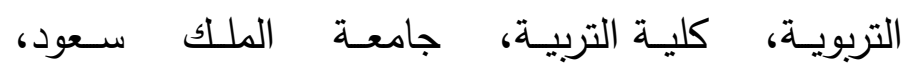

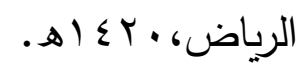

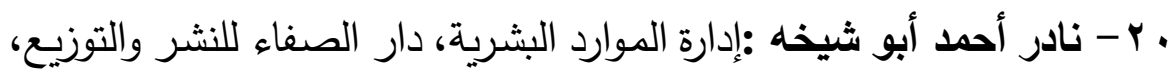

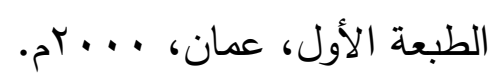

ا Y - ناصر على عحه: رؤى مستقبلية لتطوير أداء المعلم في ضوء المستويات المعياريـة لتحقيق الجودة الثـاملة، المؤتمر العلمي التاسـع مئح

عشر للجمعية المصرية لتطوير المناهج وطرق التدريس، المجلد الأول، جامعة عين شمس،القاهرة، 0 . . ب م.

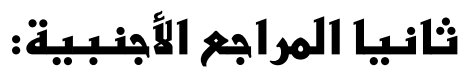

22- Campbell,J.p. (2005). Evaluating Teacher Performance In Higher Education: The Value Of Student. Unpublished doctoral dissertation, University of Central Florida, Orlando, Florida.

23- Garth-Young, B.L. (2007). Teacher evaluation: Is it an effective practice? A survey of all junior high/middle school principals in the state of Illinois. Unpublished doctoral dissertation, Loyola University Chicago, Illinois, United States. 
24- Scott, C. A. (2005). Building principal perceptions and use of various teacher performance evaluation methods in large Arkansas school districts. Unpublished doctoral dissertation, The University of Arkansas, Arkansas, United States.

25- Wilder, R.M. (2006). Evaluating evaluators: The qualifications of principals to evaluate teachers in accredited international schools in. 